\title{
Unreinforced and confined masonry buildings in seismic regions: Validation of macro-element
}

models and cost analysis

Rui Marques ${ }^{1,2, *}$ and Paulo B. Lourenço $0^{2}$

${ }^{1}$ Engineering Department, Pontifical Catholic University of Peru, Av. Universitaria 1801, San Miguel, Lima 32, PERU

${ }^{2}$ Institute for Sustainability and Innovation in Structural Engineering, University of Minho, Campus de Azurém, 4800-058 Guimarães, PORTUGAL

*Corresponding author: marquesmnc@ sapo.pt; Tel.: +511 6262000 4605; Fax: +511 62620002813

Abstract: Modern design of buildings requires accounting for sustainability aspects using a life-cycle perspective, but also the early design phase where earthquake actions have a significant influence concerning the structural design. Recently, the seismic evaluation of masonry buildings using macroelement modeling approaches became popular, by applying performance-based assessment procedures through nonlinear static (pushover) analysis methodologies. This work addresses the validation for these approaches referring to two full-scale masonry structures tested under quasi-static lateral loading and almost unknown in the literature. The experimental behavior of tested unreinforced masonry (URM) and confined masonry (CM) structures is compared against the pushover response of the corresponding computational models. Then, referring to typical housing in southern Europe and its usual design with a reinforced concrete (RC) structure, the validated assessment tools are employed to evaluate the earthquake-resistant possibilities of URM and CM solutions, namely in terms of maximum applicable ground accelerations. The masonry solutions are also compared in terms of construction costs against the RC typology. The considered analysis tools present a good agreement when predicting, satisfactorily, the experimental test behavior, thus being able to be used in performance-based design. With respect to the studied housing, the predicted pushover responses for the masonry structures denote capacity to resist earthquakes adequately. These structures allow also a significant cost reduction (up to $25 \%$ ) against the RC, thus appearing to be competing alternatives.

Keywords: macro-element models, quasi-static tests, unreinforced masonry, confined masonry, seismic assessment, cost analysis 


\section{Introduction}

The building sector has a large influence in the economy, totalizing about $10 \%$ of the GDP in European countries. Moreover, people live most of their lives inside buildings, while housing has a major weight in the budget of families and of the banking system. Low-to-medium rise buildings (up to 3 storeys) are the more frequent typology for housing, requiring then particular attention in developing sustainable solutions for construction. The adopted structural solution represents itself an important initial investment for housing and is the focus of the present paper.

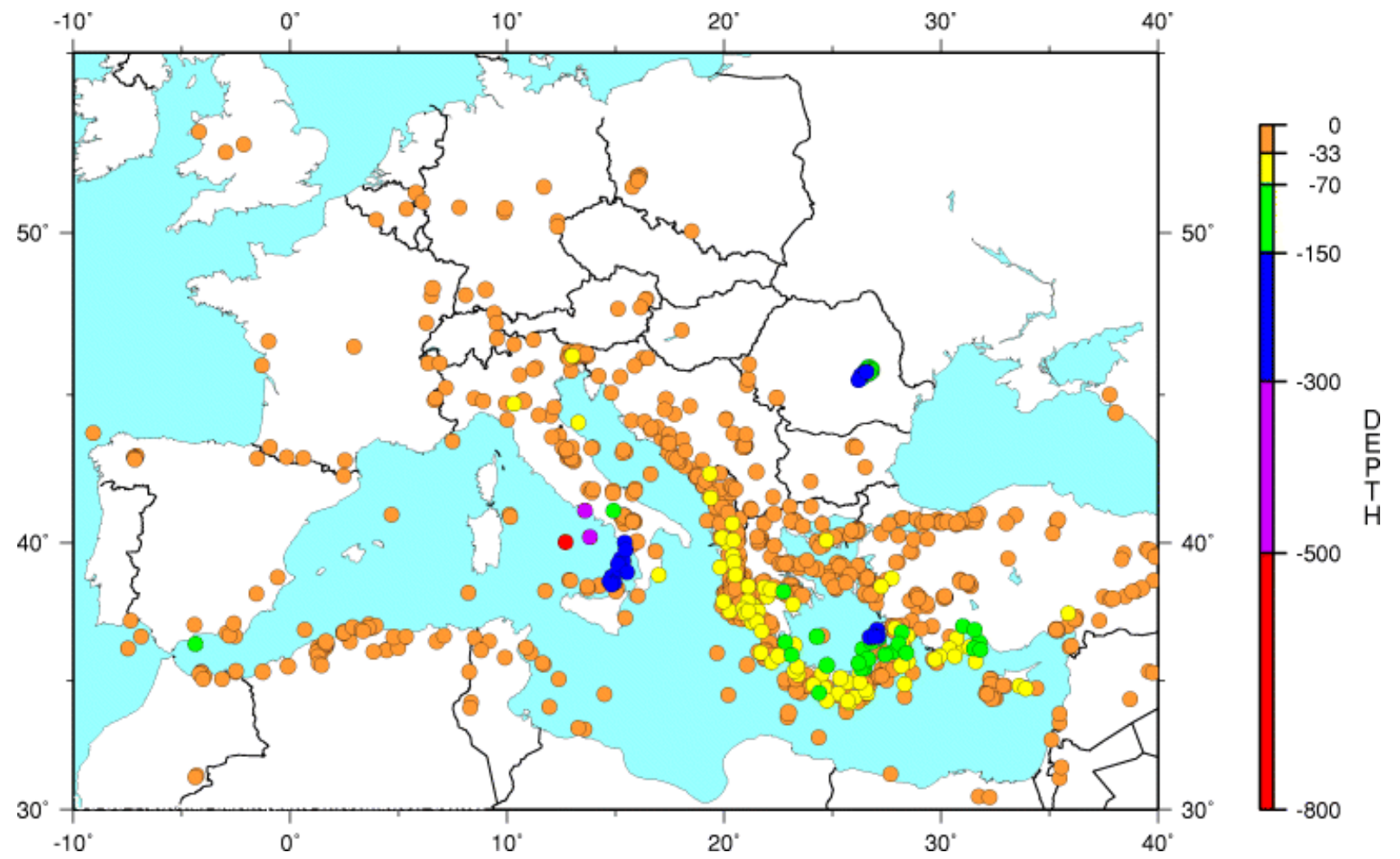

Figure 1. Earthquakes in Europe with magnitude greater than 5 in the period 1973-2006 [Source: U.S. National Earthquake Information Center]

Buildings need to provide for welfare, health and safety of occupants. The occurrence of strong earthquakes in the Euro-Med region, see Fig. 1, even in moderate seismicity zones (e.g., the 2011 Lorca earthquake in Spain), highlighted the consequences of poorly designed earthquake resistance structures regarding: damages, injured people, deaths, post-earthquake traumas and reconstruction costs. It is known that earthquakes can take place all over the 
world causing large losses. The seismic action needs then to be adequately considered in the design of buildings, as addressed in recent methodologies and codes for seismic safety assessment of structures, e.g. [1-3].

There is an important challenge to be addressed today, which is combining sustainability and earthquake resistance. Cost-effective structural solutions can present higher vulnerability to earthquakes, as is typically the case of unreinforced masonry (URM) when compared to reinforced concrete (RC), which became the dominant structural solution in many countries, even for small houses in low seismicity regions. Still, in many cases and taking into account the seismic performance, URM or confined masonry (CM) structural solutions can be alternatively used for low-rise buildings.

The sustainability concept is often applied in the fields of construction economy or green building as whole, with less consideration of the adopted structural typology, also in terms of earthquake resistance. Framed RC structures, given their prevalence, are commonly assumed as reference for sustainable building design. However, the optimization of the building performance in general (economy, safety, durability, etc.) calls for a broad approach to sustainability, which needs to account necessarily for the structural typology.

This study addresses the design of masonry building structures, focusing on the seismic assessment, but economy aspects in construction are also discussed. Different tools for seismic assessment and design of masonry buildings are presented and validated against experimental results obtained from tests on full-scale structures. A validation of recently proposed macro-element approaches for URM structures is made through a comparison with experimental results. Furthermore, the study includes an experimental validation of a new modeling approach recently adopted for CM buildings. The performed benchmarking allows to extend significantly the application domain for the studied modeling approaches. 
Afterward, by applying these tools in the performance-based seismic assessment of a typical dwelling in Europe, URM and CM structural solutions are evaluated and compared against the solution in RC. Referring to typical single family housing in southern Europe and its usual design with a RC structure, the validated assessment tools are employed to evaluate the earthquake-resistant possibilities of URM and CM solutions showing that the corresponding structures appearing to be competing alternatives to RC structures. This is an aspect of considerable relevance also concerning sustainability in construction.

\section{Macro-element models for masonry}

Masonry structures present specific and diverse bond typologies, for which several modeling approaches have been adopted. In the academic-research field the modeling of masonry buildings has been applied using two different scales, namely the micro- and macro-element approaches, see Lourenço [4]. Engineering applications of these academic-based approaches can be found e.g. in [5-6], but they remain confined to a rather small number of experts. The concept of using structural component models designated by macro-element modeling for masonry structures was introduced in the 1970s by Tomaževič [7] and applied to perform seismic assessment. This concept is the one addressed next, given the easy implementation of material laws and of the formulation of structural equilibrium. The adopted structural component discretization largely reduces the number of degrees-of-freedom in relation to the traditional micro- or macro-modeling approaches, allowing for more resource- and timeefficient computations and making them attractive to practitioners. In the following, the available models are briefly described and validated, for unreinforced and confined masonry.

\subsection{Models for unreinforced masonry (URM)}

Recently, and mainly in Italy, several user-friendly computer codes based on macro-elements have been developed for assessing the seismic safety of URM buildings. Marques and 
Lourenço [8] benchmarked the ANDILWall/SAM II [9], the TreMuri [10] and the 3DMacro [11] software codes, and provided the basic description of the macro-element formulation and assemblage used in these methods. Briefly, SAM II and TreMuri are based on frame-type modeling by using one-dimensional macro-elements, while the 3DMacro is based on a discretization with two-dimensional discrete elements, as shown in Fig. 2.

Frame-type approaches are based in the discretization of the structure into piers and spandrels, which are connected by rigid nodes hence creating an equivalent frame. Assemblage and solution for this approach can be implemented similarly to framed structures, by applying conventional methods of structural mechanics. However, these methods present limitations concerning the simulation of the interaction between macro-elements through rigid nodes, and the modeling of the cracked condition of panels, which is lumped at middle/end parts of the element. These aspects are improved when considering the two-dimensional approach in 3DMacro by using a set of non-linear springs that allows simulate the planar response of masonry panels and its interaction and cracking within the entire element (Fig. 2c). The seismic assessment by these methods is performed through performance based approaches, i.e. nonlinear static (pushover) analysis, according to recent design codes [1-3].

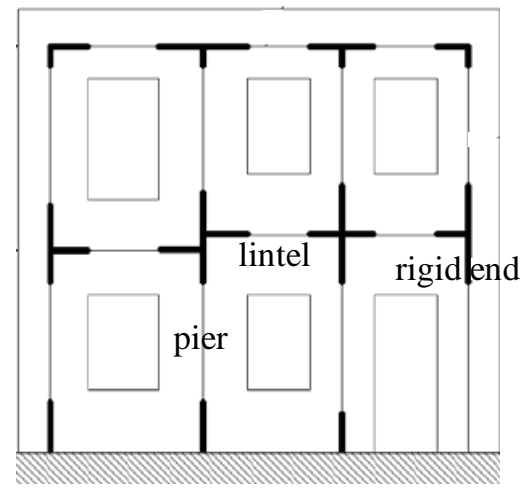

(a)

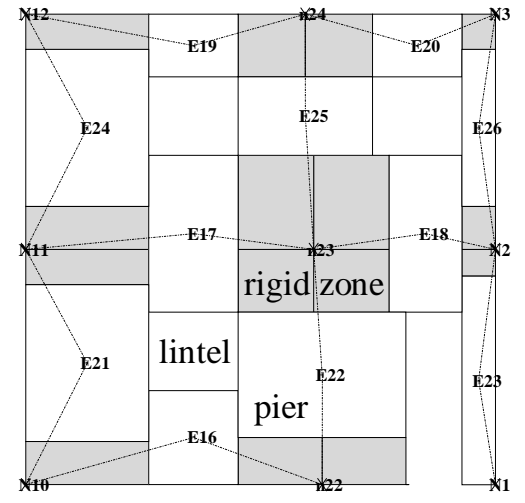

(b)

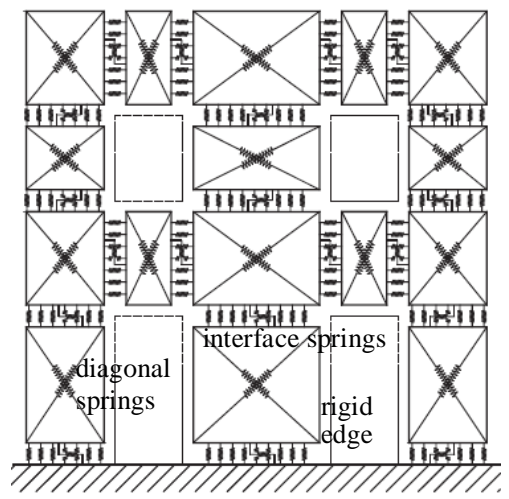

(c)

Figure 2. Schematization of wall models in (a) SAM II, (b) TreMuri and (c) 3DMacro

The methods above were developed in a sequential process, from macro-element idealization, through wall assemblage definition to full building simulation. The validation 
process for these methods was made with experimental testing and more advanced computations, in individual masonry panels, full plane masonry walls and three-dimensional structures. With respect to the entire building simulation, the masonry building tested in Pavia under quasi-static loading by Magenes et al. [12] is a much used benchmark for validation. But the validation process is not easy due to the large variability of masonry materials and due to the importance that the complex structural organization in full buildings might assume. On the other hand, rather few quasi-static tests on URM buildings have been carried out allowing this validation: another example is given by Yi et al. [13] for typical URM in the mid America region. Many URM building models have been tested in shaking tables, but, in general, the dynamic experimental behavior is difficult to compare with the pushover response.

Here, an experimental test with lateral cyclic static loading on a URM structure, which received almost no attention in the literature so far, is adopted to evaluate the predictions by the pushover analysis using the macro-element models. The tested structure, presented in Cappi et al. [14], is constituted by a couple of identical masonry walls made of solid ceramic bricks, with a thickness of $0.375 \mathrm{~m}$ (in the parapets, only $0.125 \mathrm{~m}$ thickness) and a specific weight of $18.0 \mathrm{kN} / \mathrm{m}^{3}$. The two walls are in parallel position and are weakly connected through timber joists, as shown in Figure 3. The walls are subjected to a vertical load of 100 $\mathrm{kN} / \mathrm{m}$, applied using steel tie-rods anchored on a reinforced concrete beam in the top of the wall. The walls were then, separately, subjected to cycles of an increasing horizontal force $P$ also applied at the top beam level.

The known strength properties for the masonry, obtained from experimental tests, are a tensile strength $f_{t}$ of $0.08 \mathrm{MPa}$ and an internal friction angle $\phi$ of $36^{\circ}$, which allow using the diagonal shear strength criterion by Turnšek and Čačovič [15]. The elastic moduli were estimated by inverse fitting the numerical results to replicate the initial stiffness of the structure, assuming a ratio between the longitudinal and transversal moduli, respectively $E$ 
and $G$, of 6 (the value given in the Italian code OPCM 3431/2005 [16] for solid brick masonry). The resulting values for $E$ and $G$ are, respectively, 3200 and $533 \mathrm{MPa}$. The masonry compressive strength $f_{m}$ was obtained from the formula in EC6 [17] for short duration actions, as $E / 1000$ or $3.2 \mathrm{MPa}$.

The wall-type structure was simulated in the software codes indicated above, according to the computational models given in Figure 4. Subsequently, pushover analysis provides the capacity curve. Note that for the TreMuri software two different approaches for the macro-element shear-displacement response were considered, namely a bilinear law and the approach of Gambarotta and Lagomarsino [18], which are hereafter designated as 3Muri and TreMuri models. The capacity curves obtained are compared in Figure 5 against the experimental response envelopes for the two tested walls. In general, all the models present a satisfactory prediction of the experimental capacity curve, particularly in terms of the initial stiffness and of the base shear strength. Furthermore, the 3Muri, TreMuri and 3DMacro models are capturing the stiffness decay in the second part of the experimental response. All the models predict a drop in strength for a displacement of $17.5-20 \mathrm{~mm}$ and, with the exception of SAM II, a significant loss of strength (about 20\%) for a displacement of 26.5-30 $\mathrm{mm}$. In the case of SAM II, this drop of strength occurs for a displacement of $40 \mathrm{~mm}$.
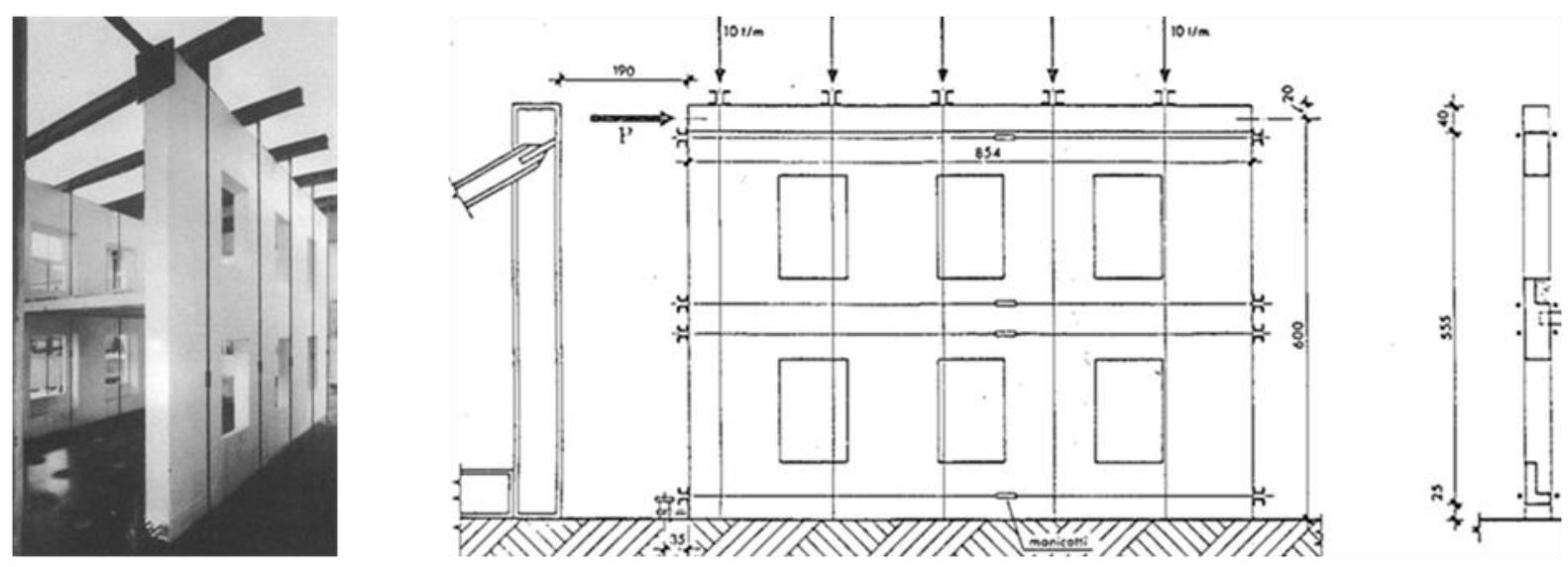

Figure 3. Views of the masonry structure tested under lateral static loading [14] 


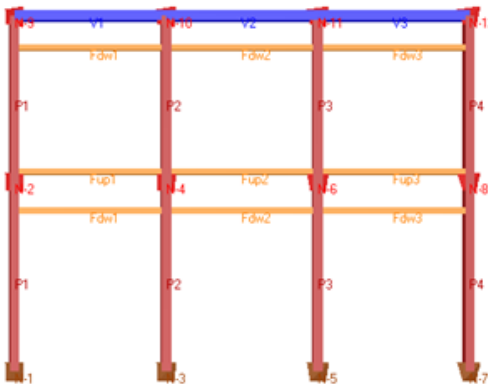

(a)

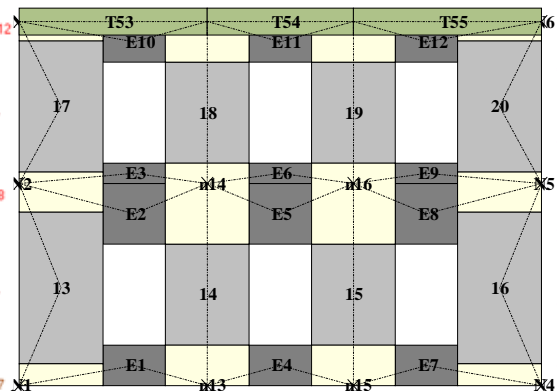

(b)

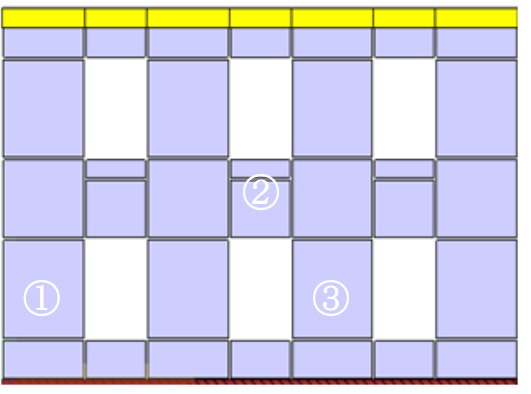

(c)

Figure 4. Wall models in (a) ANDILWall/SAM II, (b) TreMuri and (c) 3DMacro

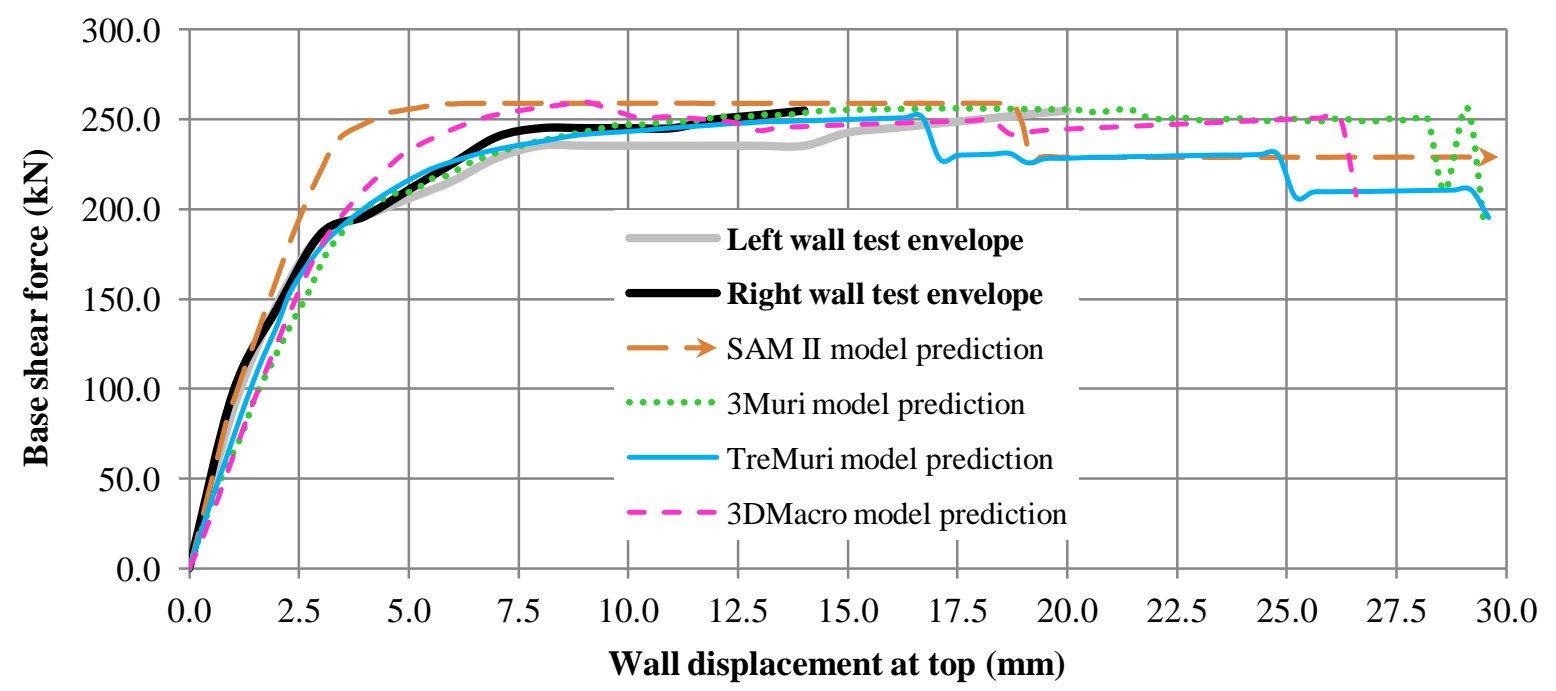

Figure 5. Experimental envelopes and capacity curves obtained for the several models

More than the good approximation observed in the global response of the structure, it is interesting to investigate the load evolution on the different wall elements, and also their damage progress in correspondence with the applied load. Next, the evolution of the axial load $N$ and of the shear force $V$ in the panels labeled in Figure $4 \mathrm{c}$ is discussed. These are panels in the ground level: the leftmost pier (Label 1), the center spandrel (Label 2) and the right-center pier (Label 3). The evolution of the $N$ and $V$ versus the wall displacement at top is presented in Figures 6 and 7.

Concerning the pier panels, the evolution of the axial load shown in Figure 6a is, in general, similar for all the models. Note that for the TreMuri (Gambarotta-Lagomarsino shear law), the computed axial force is reduced with respect to the elastic value, to account for the deterioration of piers in compression as proposed by Penna [19]. Regarding the shear force, 
Figure $6 \mathrm{~b}$ shows the strength sensitivity to the material degradation behavior considered in the case of the TreMuri and 3DMacro models, which is evident for Pier 1. Observing the two graphs, it is clear that the evolutions of axial and shear force are directly related, which calls for an adequate approach in the evaluation of the axial force.

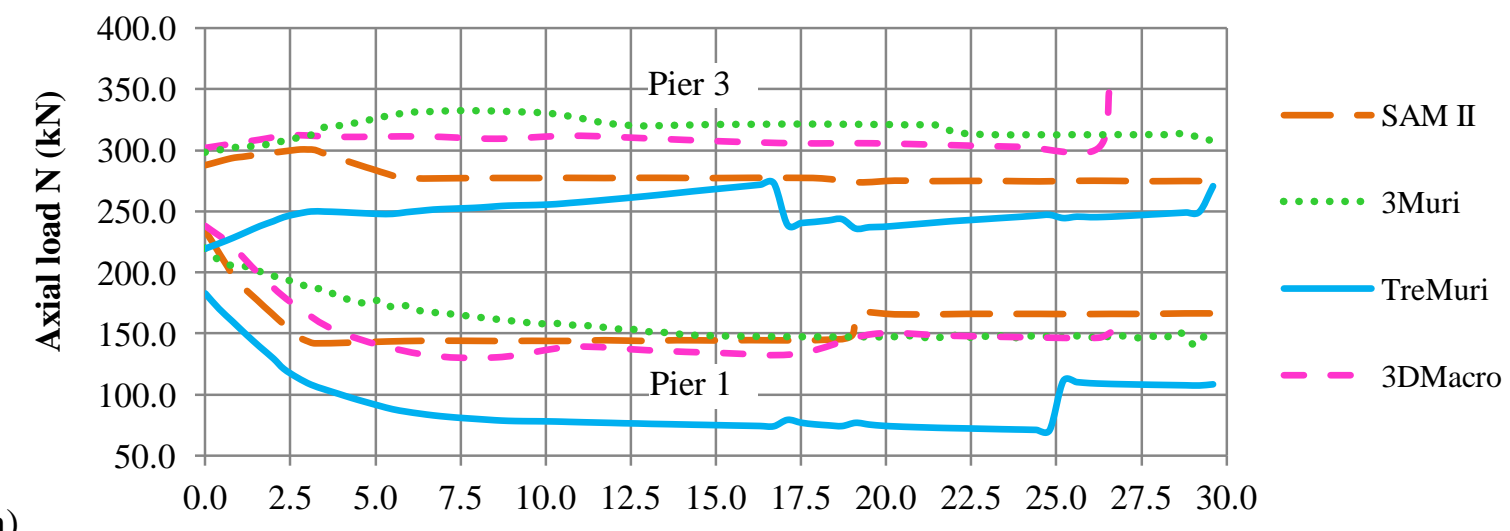

(a)

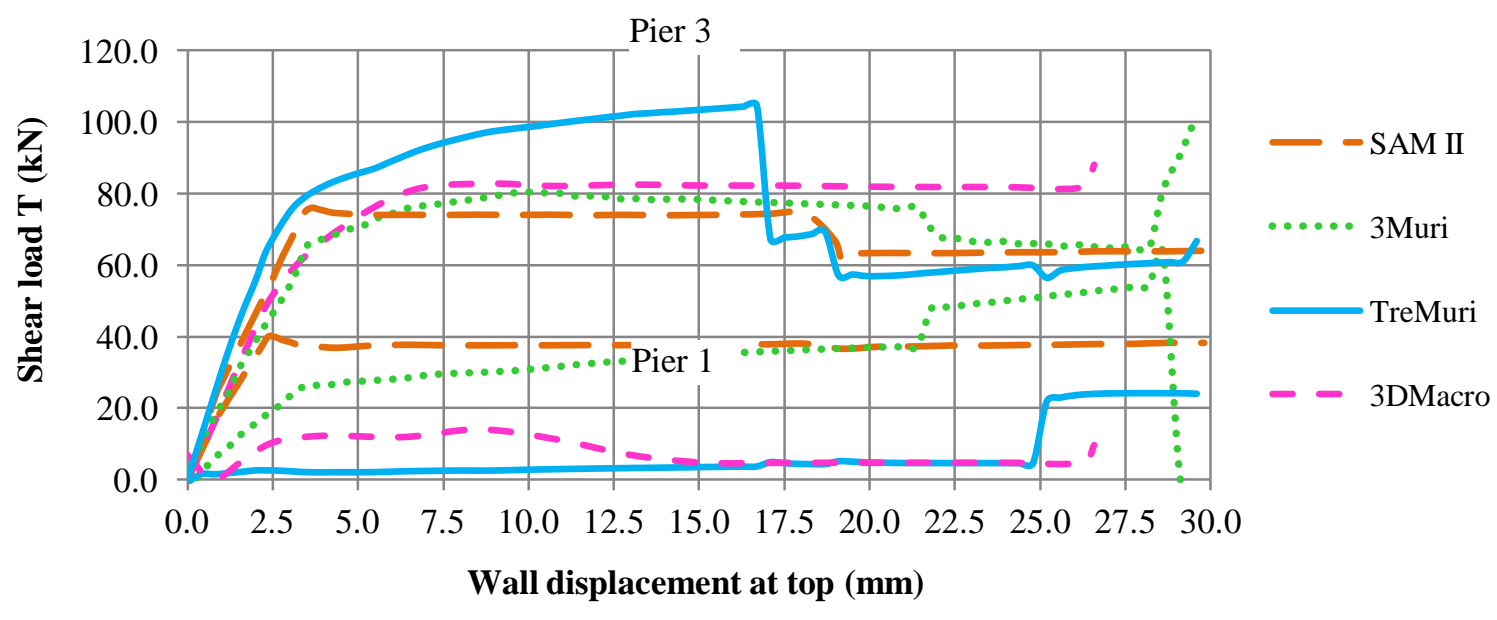

Figure 6. Evolution of the (a) axial and (b) shear forces in the piers

For the center spandrel, the evolution trend of the axial and shear forces shown in Figure 7a provides significant disagreement between the models, concerning namely the extreme values for the axial load, once that the TreMuri model provides significantly higher values than the others and SAM II provides a zero value. This disagreement is due to different assumptions in the methods for the spandrel behavior and the interaction between the piers. In the case of the frame-type models the spandrel is purely connected to the piers through rigid nodes, and for the SAM II without considering the axial load to the spandrel, while in the 
3Muri and TreMuri models the contribute of axial compression is considered to compute the shear strength of the spandrel. This aspect is clearly a limitation of these methods, since experimentally it can be observed that the lateral response of URM walls is largely influenced by nonlinear behavior of spandrels, namely due to diagonal cracking as verified for the present wall, and also to flexural damage [20]. Thus, the 3DMacro model by considering explicitly both diagonal shear and flexural mechanisms for the spandrel element probably provides a more accurate approximation. According to Cappi et al. [14], the damage in the walls was typically by diagonal cracking and was initiated in the center spandrel (Fig. 7b).
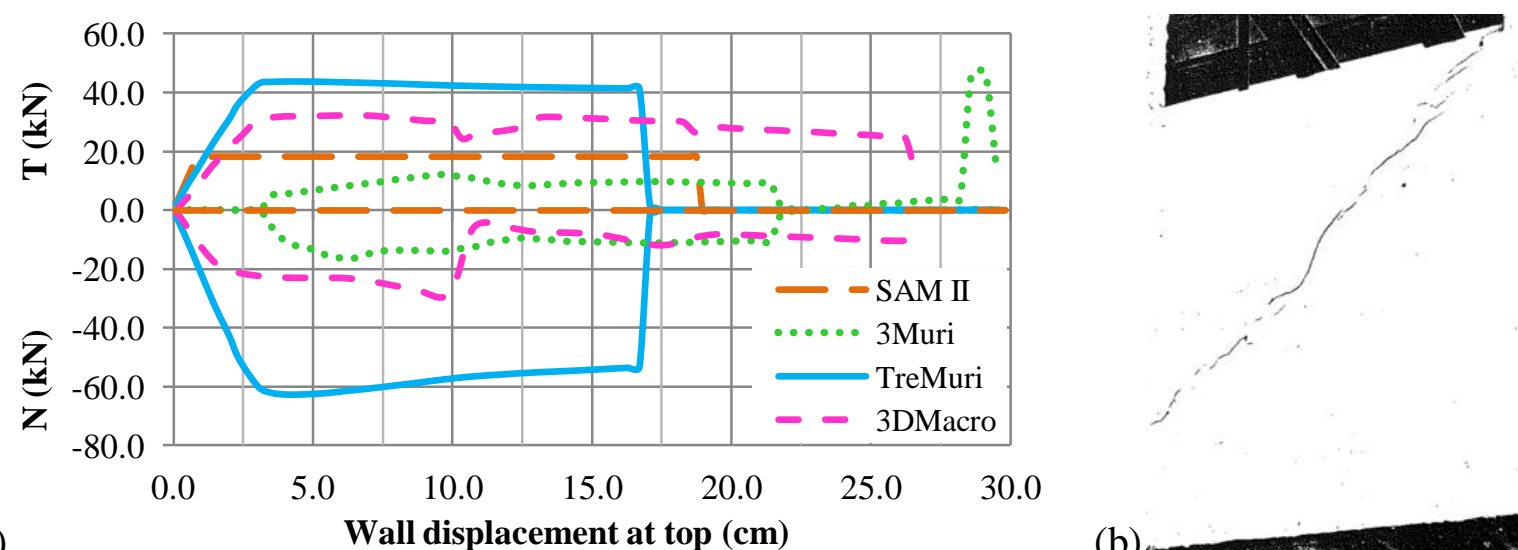
(a) Wall displacement at top $(\mathrm{cm})$ (b)

Figure 7. Response of the center spandrel: (a) evolution of the axial and shear forces; (b) crack in the experimental model [14]

The predicted sequence for the wall deformed shape and damage is summarized in Figure 8, for every model and in correspondence with wall displacement levels of $7.5 \mathrm{~mm}$ (yielding), $18.5 \mathrm{~mm}$ (end of the first yielding stage) and ultimate displacement (strength loss of 20\%). A wider sequence for the wall predicted behavior is presented in Marques [21]. The known experimental results describing the wall deformed shape and damage are limited, but according to Cappi et al. [14] the wall response incorporates wall- and frame-type behavior patterns. Due to the wall-type behavior, the overturning action generates tension in the left piers and compression in the right piers, while the spandrels are essentially subjected to shear. 
Due to the frame-type behavior, the four bottom-to-top columns are subjected to similar moments, while the cross members are compressed and bent.

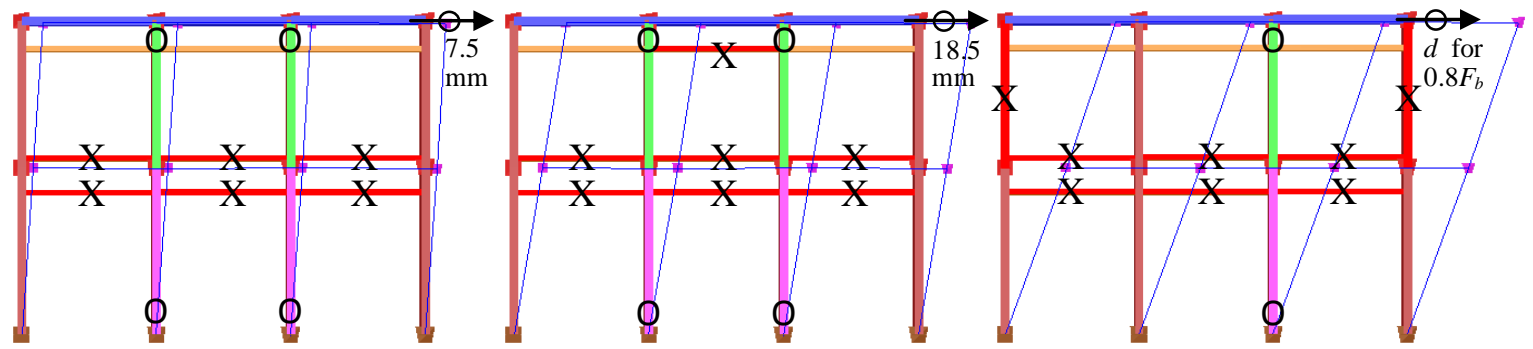

(a) Damage in panel ends: $\mathrm{O}$ flexural at base $\mathrm{O}$ flexural at top $\mathrm{X}$ shear at base and top
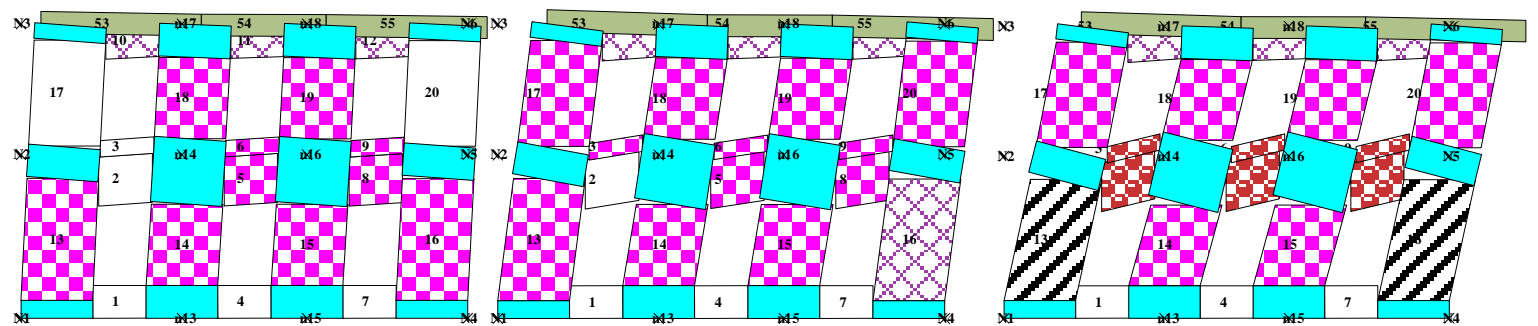

(b) $\square$ elastic $\square$ plastic by shear $\square /$ shear failure $\square$ plastic by flexure 59 flexural failure
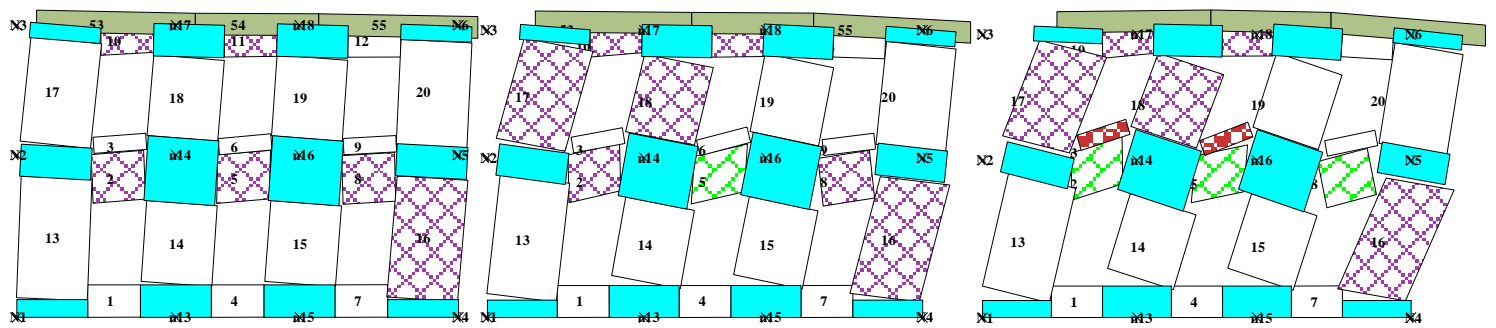

(c)

Shear damage: low $\triangle X X X$ moderate $\angle Z Z Z$ high $\$ 080$ extreme
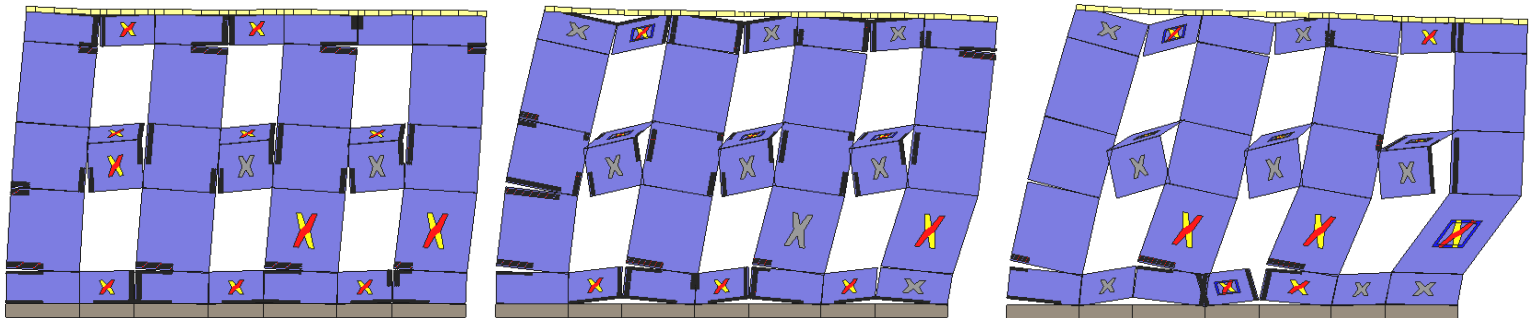

(d) $\$$ diagonal cracks $\$$ closed cracks $\$$ diagonal failure crushing $\square$ tensile cracks

Figure 8. Wall deformed shape and damage according to models: (a) SAM II, (b) 3Muri, (c) TreMuri and (d) 3DMacro (50 times magnification)

Concerning the deformed shape, the SAM II and 3Muri models provide a similar trend by deforming linearly along the height. On the other hand, the TreMuri and 3DMacro models present an identical first level mechanism. In terms of damage the same groups are identified, with the first group (SAM II and 3Muri) presenting initial damage mostly by flexure, even if 
some panels fail latter by shear, and the second group (TreMuri and 3DMacro) presenting shear damage in selected panels (e.g. the lower pier on the wall right), associated with rocking of piers at the first level on the wall left. In the experimental test, the earliest damage was due to shear on the intermediate horizontal cross member, and which resulted seriously damaged at the end of the test. Damage to this member is identified by all the models.

The model grouping in terms of the predicted response seems to be associated to the assumptions adopted by the models, as the first group considers one-dimensional elements with a bilinear response, while the second considers a bi-dimensional domain for the material constitutive law. From the experimental and analytical results presented in Cappi et al. [14], namely the identified diagonal shear damage for the central spandrel and a stronger deformed shape at the first level, it seems that the second model group better agrees with the experimental response. For this reason, Figure 8c-d is assumed to represent the best approximation to the experimental damage.

\subsection{Models for confined masonry (CM)}

$\mathrm{CM}$ is a particular case of masonry structures, even if it presents some similarity with reinforced concrete $(\mathrm{RC})$ structures due to the presence of a frame. $\mathrm{CM}$ is characterized by casting of the RC elements only after the masonry works, which provides a good connection between the confining elements and the masonry panels due to the combination of bond effects, shrinkage of the RC elements and the fact that the vertical dead load is transferred to the walls. The interaction behavior between the confining elements and masonry through the existing interface is a specific aspect that needs to be considered in the response of CM walls under lateral loading. Some models have been implemented for CM structures based on a wide-column approach, e.g. [22-23], considering the interaction behavior between the confining elements and the masonry implicitly in the wall shear response. 
Micro-modeling strategies can also be used, namely based in the finite element method, to model explicitly the concrete-masonry interface, e.g. Calderini et al. [24]. Alternatively, a discrete element approach is also applicable, such as that idealized by Caliò et al. [25] originally for URM and which has been extended in the 3DMacro software [11] to model RC/steel/masonry mixed structures. This last approach uses an interface (constituted by nonlinear springs) between the masonry panels (Fig. 9a), which in the case of two neighboring $\mathrm{CM}$ panels is interposed by a frame modeled through nonlinear beam finite elements with concentrated plasticity (Fig. 9b). For the beam elements and in agreement to a given type of interaction (axial, flexural or axial-flexural), the corresponding hinges are considered according to the respective $N-M_{x}-M_{y}$ domain (such as in Fig. 9c). This approach has already been used for the simulation of a CM structure built in southern Italy after the 1908 Messina earthquake [26].

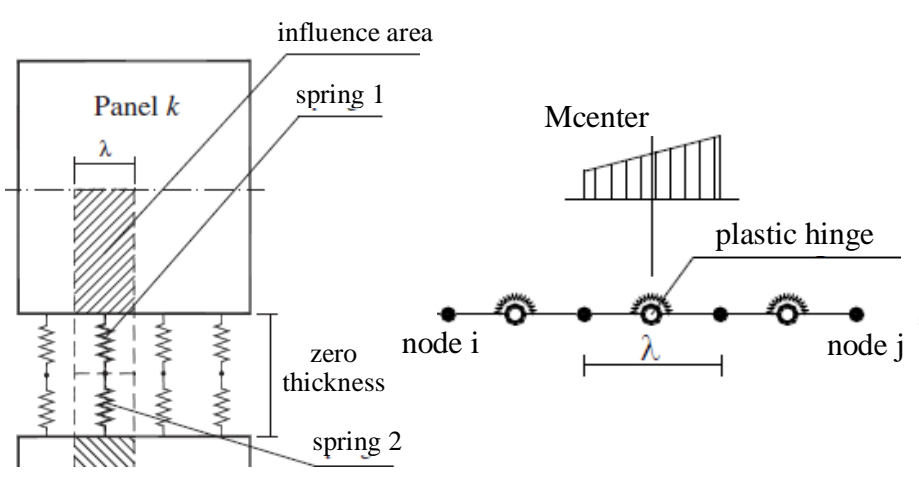

(a) (b)

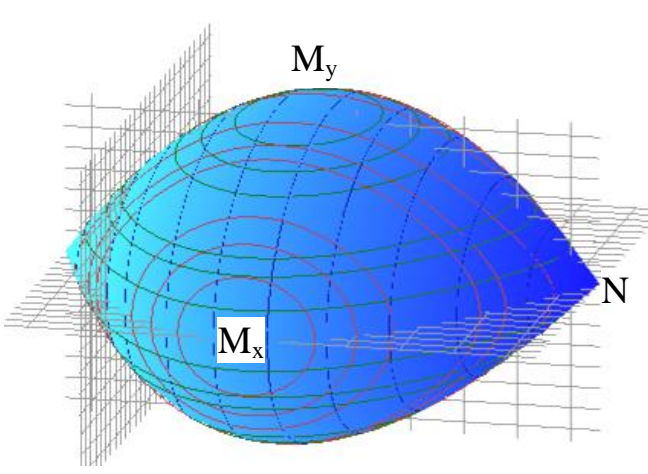

(c)

Figure 9. Discrete macro-element: (a) interface model, (b) frame element and (c) example of interaction domain $\mathrm{N}-\mathrm{M}_{\mathrm{x}}-\mathrm{M}_{\mathrm{y}}$

In this work, a building tested under quasi-static loading by Zavala et al. [27] at CISMID (Peruvian-Japanese Center for Seismic Research and Disaster Mitigation), in Peru, is considered to evaluate the discrete element approach implemented in the 3DMacro software for CM structures. The building, with the plan shown in Figure 10a, corresponds to a typical family house in Peru and features a $2.5 \mathrm{~m}$ storey height and 100 tones mass. The structure is 
built with panels of handmade clay brick confined by RC elements and floors made with prestressed ribbed slabs. The masonry presents an experimental compressive strength $f_{m}$ of 4.65 MPa, from which the diagonal shear strength was empirically estimated as $f_{m}{ }^{1 / 2}\left(\mathrm{~kg} / \mathrm{cm}^{2}\right)$ or $0.3132 f_{m}{ }^{1 / 2}$ in the standard unit $(=0.68 \mathrm{MPa})$, while the elastic and shear moduli $E$ and $G$ respectively as $400 f_{m}(=1860 \mathrm{MPa})$ and $160 f_{m}(=744 \mathrm{MPa})$, according to specifications in the Peruvian code [28].

The test set-up is given in Figure 10b, where two actuators are placed at the roof slab level and a third actuator is placed in the first storey, in order to push and pull the building cyclically. The test was conducted with mixed control, as one of the actuators in the roof was displacement controlled and the other roof actuator is force-controlled. A load pattern proportional to the building height is induced. Concerning the building damage evolution, the structure is reported to have behaved in elastic range until a $0.0625 \%$ first storey drift, while cracking in the walls started for a $0.125 \%$ drift. Large degradation was identified for a $0.5 \%$ drift, with ultimate capacity occurring for $1.33 \%$ drift.

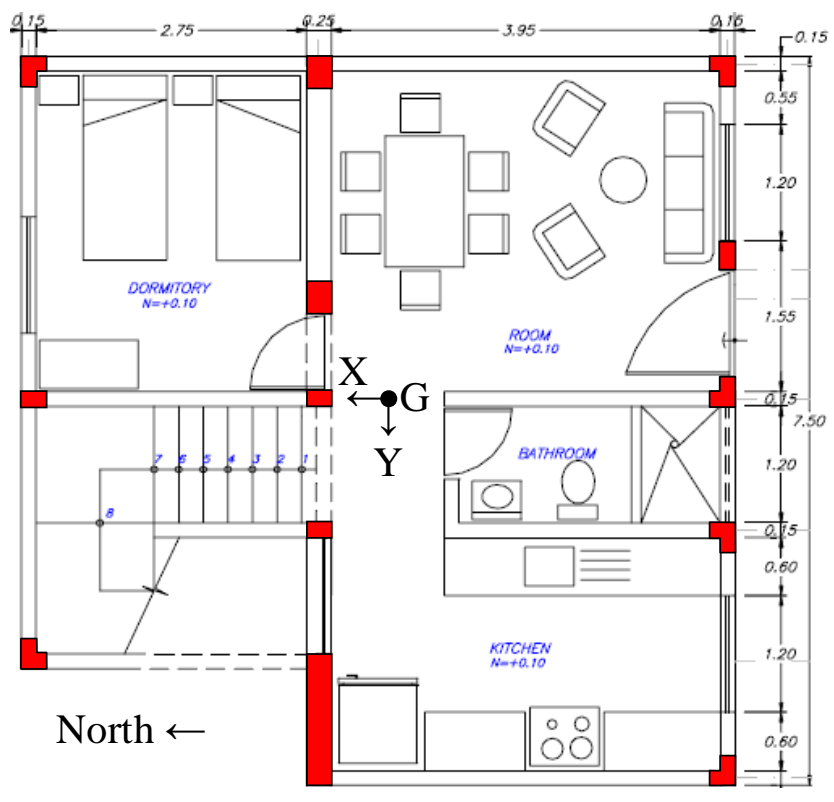

(a)

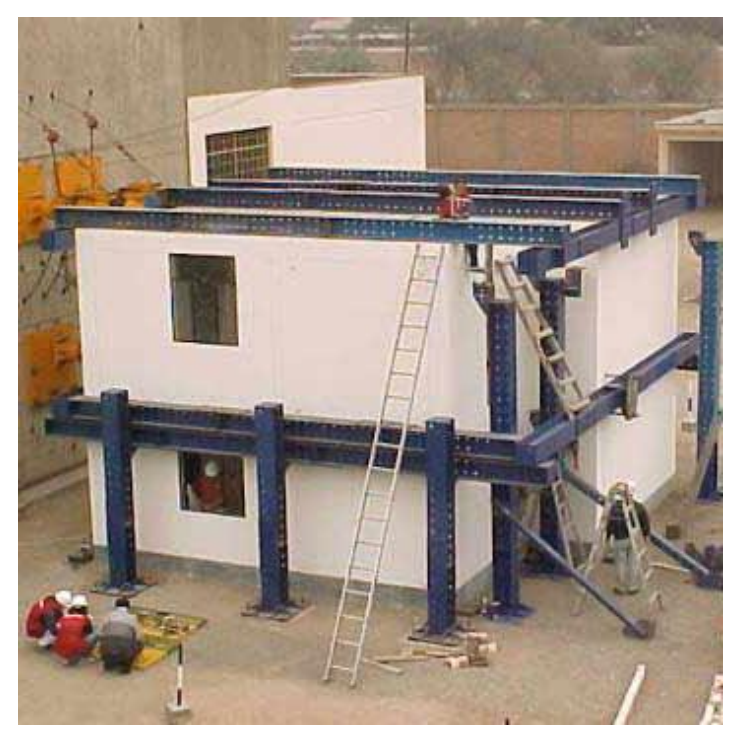

(b)

Figure 10. Building tested by Zavala et al. [27]: (a) structural plan and (b) test set-up 
The building was modeled in 3DMacro as illustrated in Figure 11. The model was then analyzed under pushover loading in the $\pm Y$ direction and considering the control point at the roof centroid ( $\mathrm{G}$ in Fig. 11). In the simulation, the predicted damage occurs mostly by diagonal cracking in the confined panels, and also with flexural plastic hinges in the confining elements. A comparison of the numerical and experimental damage evolution is shown in Figure 12 for the South wall that allows to identify globally the walls subjected to higher degradation, which are namely in the central part of the building adjacent to the openings. which aspect is probably related with force redistributions in the post-peak stage.

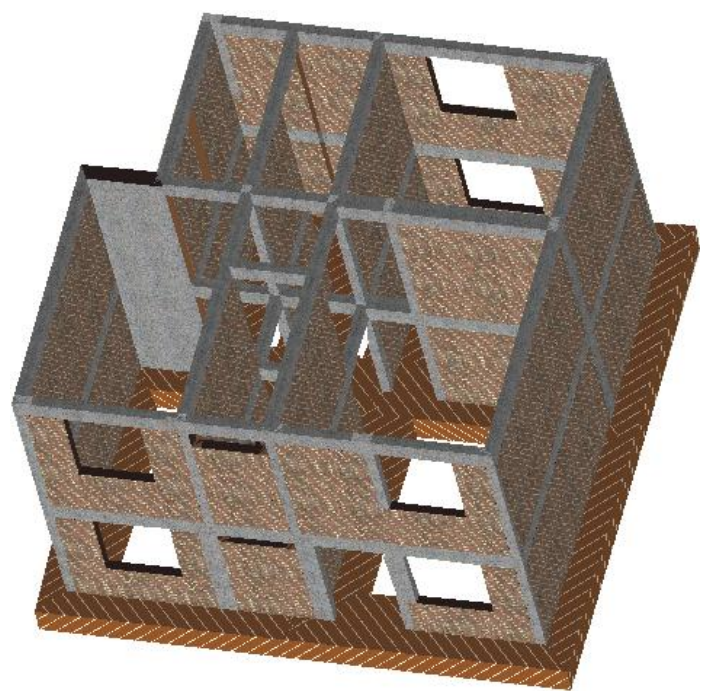

- NP: North point
- CP: Central point

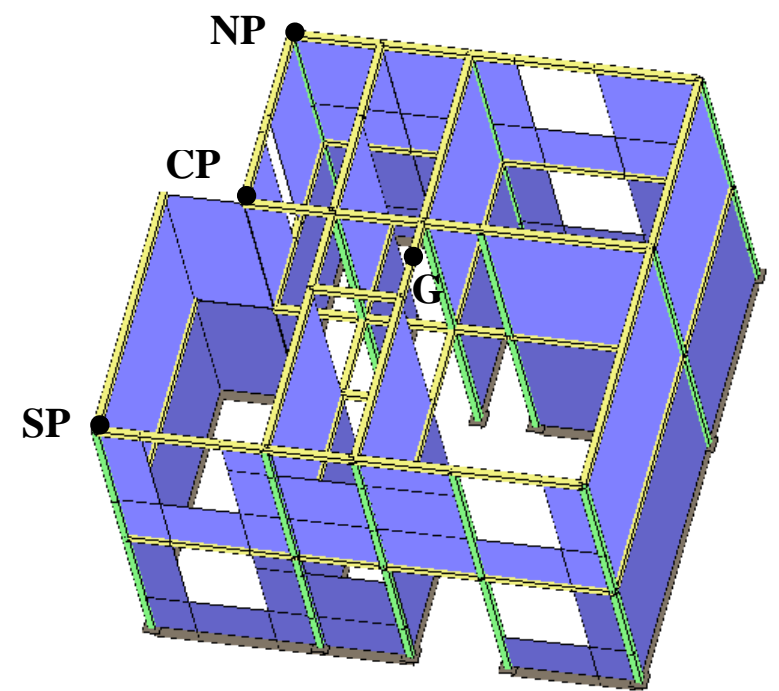

- SP: South point
- G: Roof centroid

Figure 11. Geometrical and computational models in 3DMacro of the building

The capacity curves for the building are compared in Figure 13 against the hysteretic response obtained from the test. The predicted curves present a good agreement with the experimental envelope, even if the displacement capacity was underestimated in the case of positive loading. Note that in the graphs three different experimental responses are overlapped corresponding to three different control points, placed respectively in the alignments North (blue series), South (green series) and Central (red series), see Fig. 11. If the hysteretic response for the Central alignment is adopted for comparison the agreement is better, with the 'base shear-first storey displacement' envelope for negative loading being the exception. The 
differences between the measured displacements in the three series are due to the building rotation, which is evident in the positive loading and is very important. This rotation could be captured in the prediction, even if only qualitatively as significantly smaller values are found,

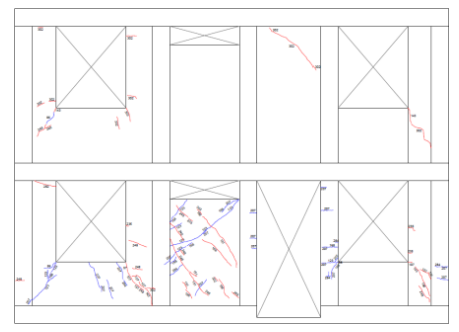

$1 / 800(3 \mathrm{~mm})$
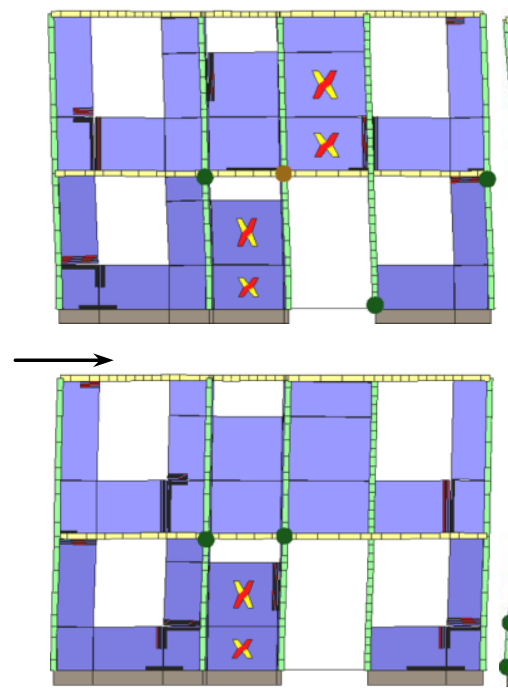

$\mathrm{X}$ diagonal cracks

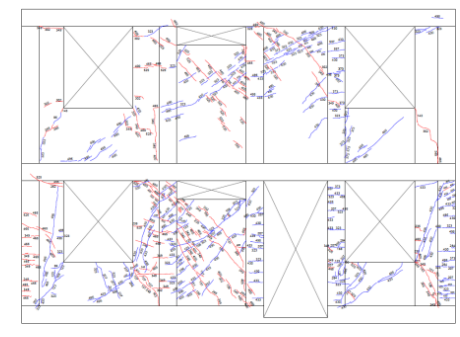

$1 / 200(12.5 \mathrm{~mm})$
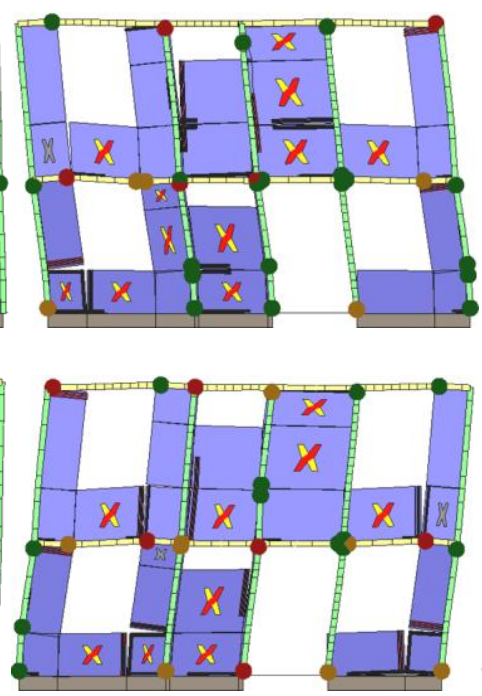

$=$ traction cracks

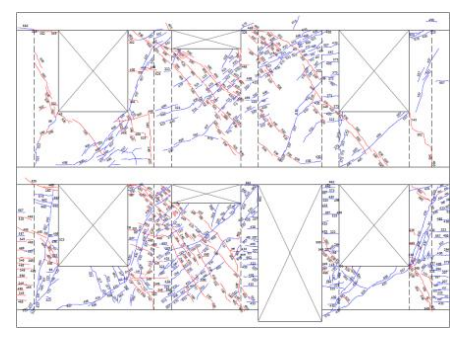

ultimate drift
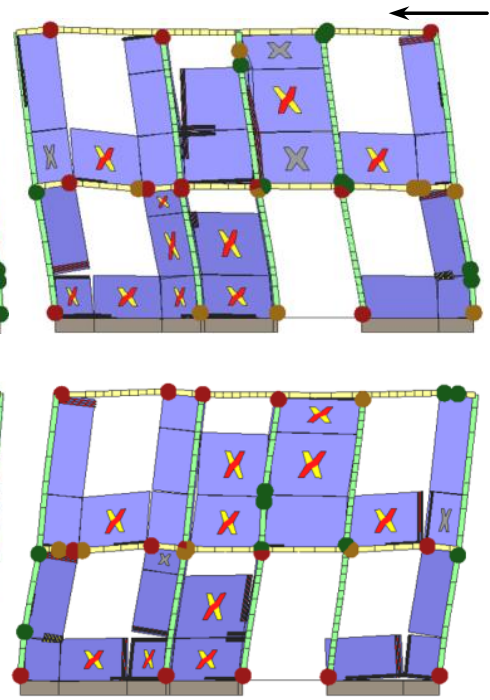

- flexural plastic hinge

Figure 12. Experimental against predicted damage in the South wall for three drift levels

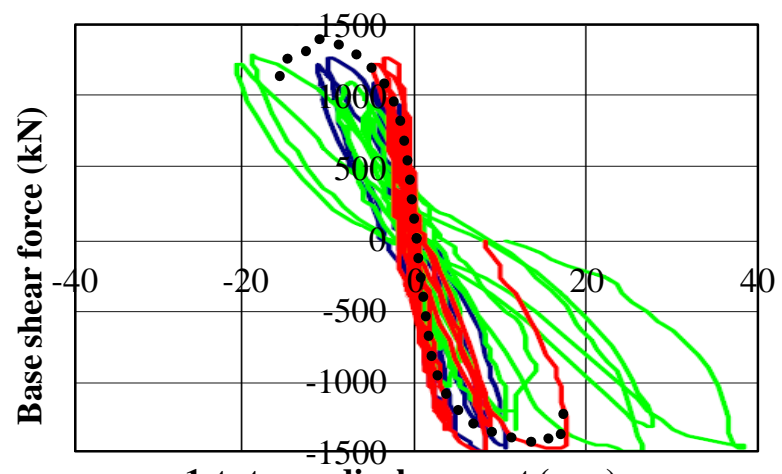

1st storey displacement (mm)

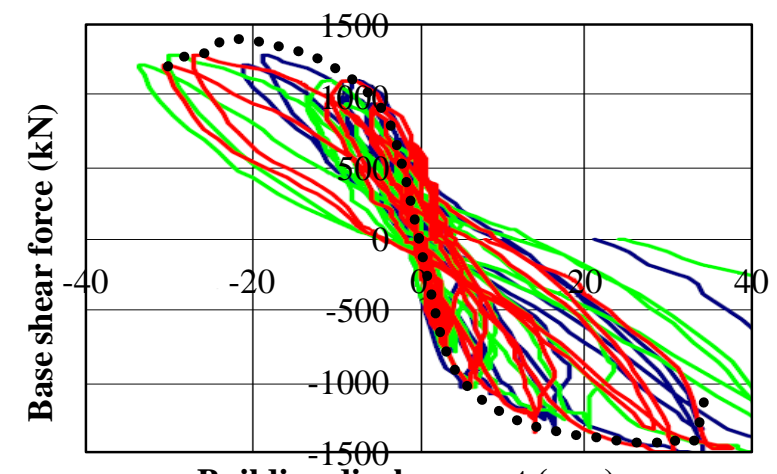

Building displacement (mm)

$\longrightarrow$ North point $\longrightarrow$ South point $\longrightarrow$ Central point Predicted at roof centroid

Figure 13. Comparison of the predicted envelopes in 3DMacro against the experimental response (color figure available online) 


\section{Comparison of different structural solutions for a dwelling}

Dwelling houses up to 2 storeys are the majority of the building stock in Europe, both in terms of existing and newly constructed buildings. The loss of masonry as a structural solution, due to an ungrounded perception of its lack of capacity to resist earthquakes and also to the dissemination of RC structures, caused a strong reduction of the use of structural masonry in new buildings. On the other hand, a large development occurred in the masonry industry, namely with the introduction of high-quality masonry systems regarding functional and mechanical features. In the academic field important efforts have been also made to develop adequate tools to account for the intrinsic nonlinear capacity of masonry structures when subjected to earthquakes. A first comparison of these tools was made by Marques and Lourenço [8] referring to a simple building configuration. In this study, the comparison is extended, concerning a real and more complex structure, addressed next.

\subsection{The case study}

The adopted two-storey semi-detached dwelling is representative of typical housing in the southern Europe, with rooms and kitchen in the ground storey and bedrooms and an office in the first storey. The house presents also a garage and a multi-level roof, as shown in Figure 14. The structure for the building was originally designed in $\mathrm{RC}$, with full drawings available in Torre [29]. In the following, alternatively to the original structure, solutions of URM and CM structures are presented and compared. The building is assumed to be constructed on type B ground (deposits of very dense sand, gravel, or very stiff clay) with prevalence to earthquakes with surface-wave magnitude lower than 5.5. Therefore, a type 2 spectrum (nearfield) with an associated soil factor $S$ value of 1.35 according to EC8 [1] is adopted.

\subsection{Unreinforced masonry solution}

URM, considering that is a simple construction technique which allows an energy-efficiency enclosure with no thermal bridges concern, is the first adopted option. In this case, a clay 
block masonry system is used with tongue and groove head joints, and with shell bedded horizontal joints. The system uses a vertically perforated block of dimensions $0.30 \mathrm{~m} \times 0.30$ $\mathrm{m} \times 0.19 \mathrm{~m}$ and complementary pieces (half-block, end-piece, corner-block, adjusting-piece and lintel-block) allowing a geometry in plan with a module of $0.15 \mathrm{~m}$. A M10 mortar prebatched, according to EC6 classification [17], is used for the joints. The structural plans for the proposed solution are presented in Figure 15, which show the bond in the first course and the second course arrangement around the wall crossings.

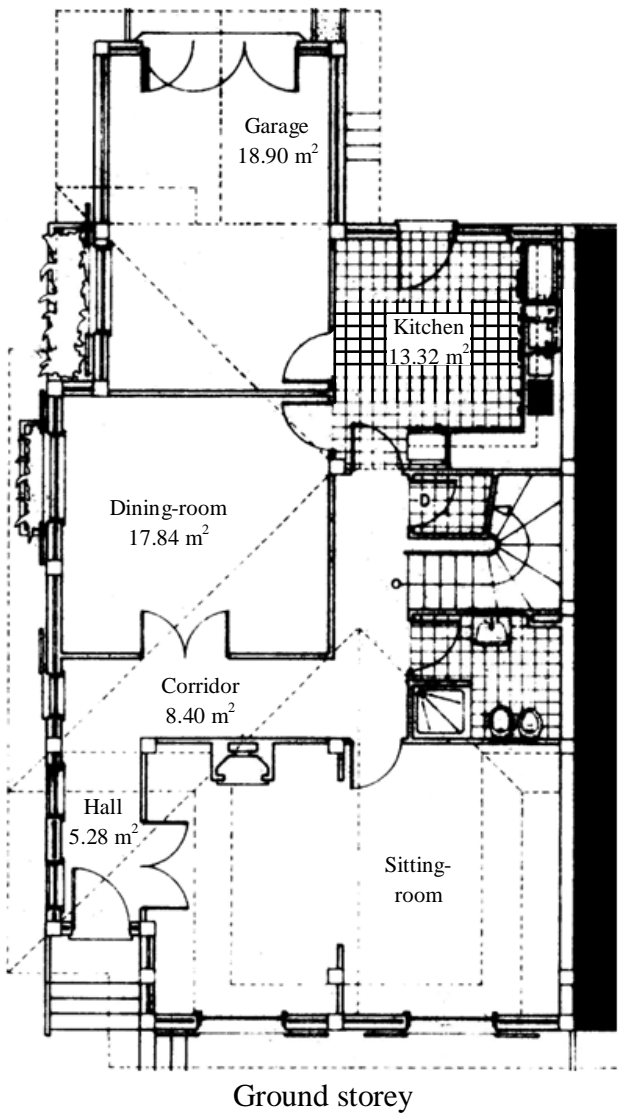

Ground storey

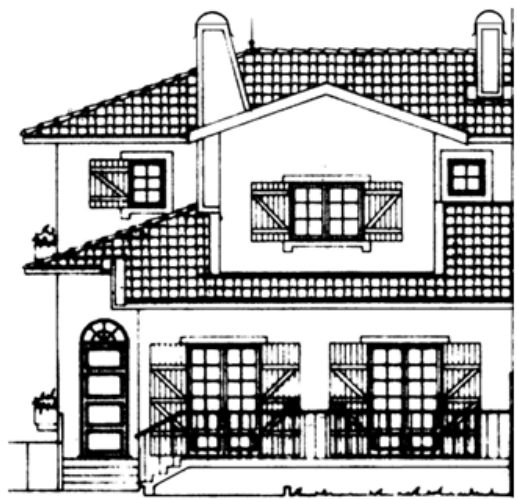

Front elevation

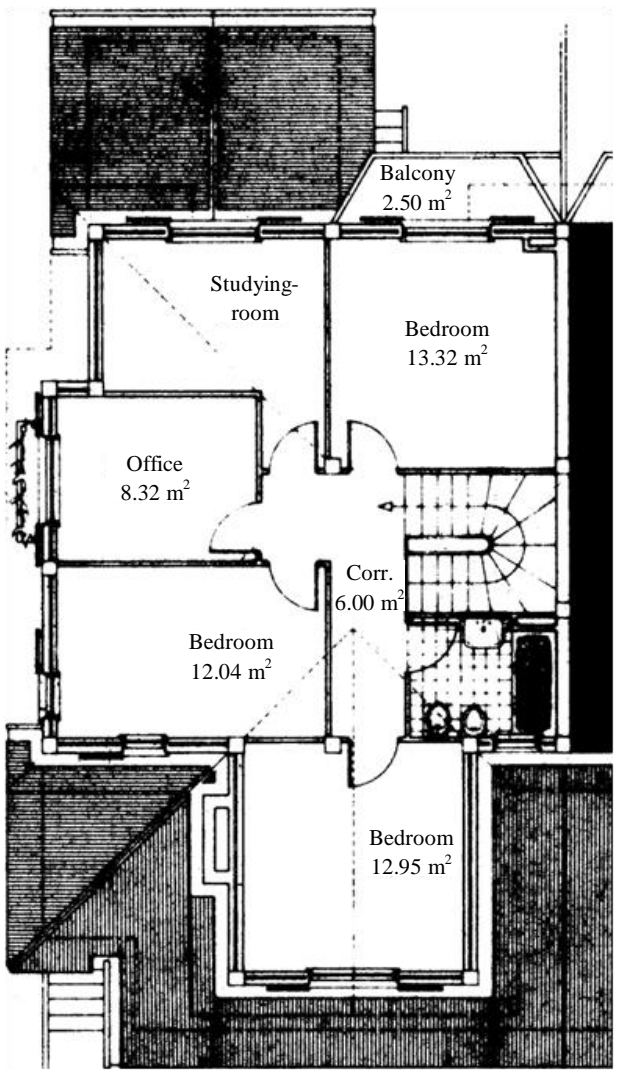

First storey

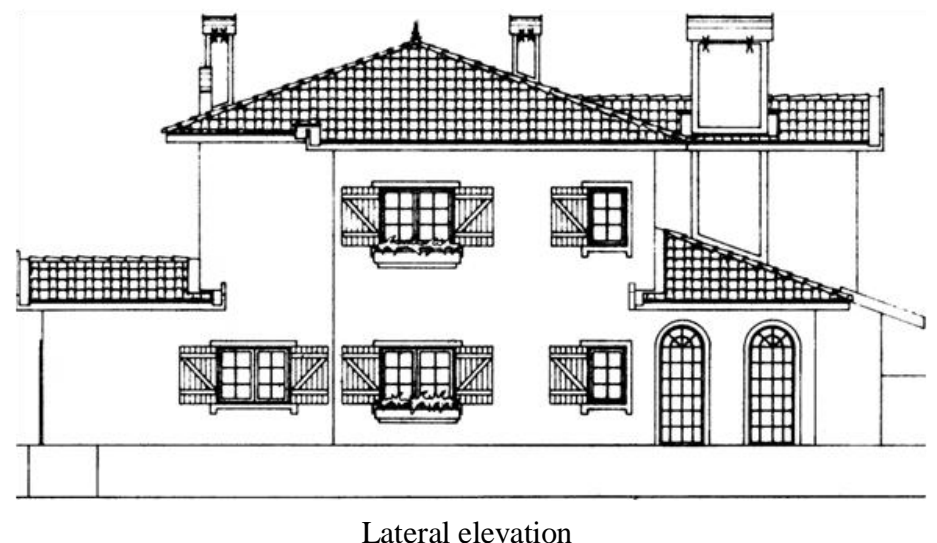

Lateral elevation

Figure 14. Architectural drawings of the dwelling: plans and elevation views 

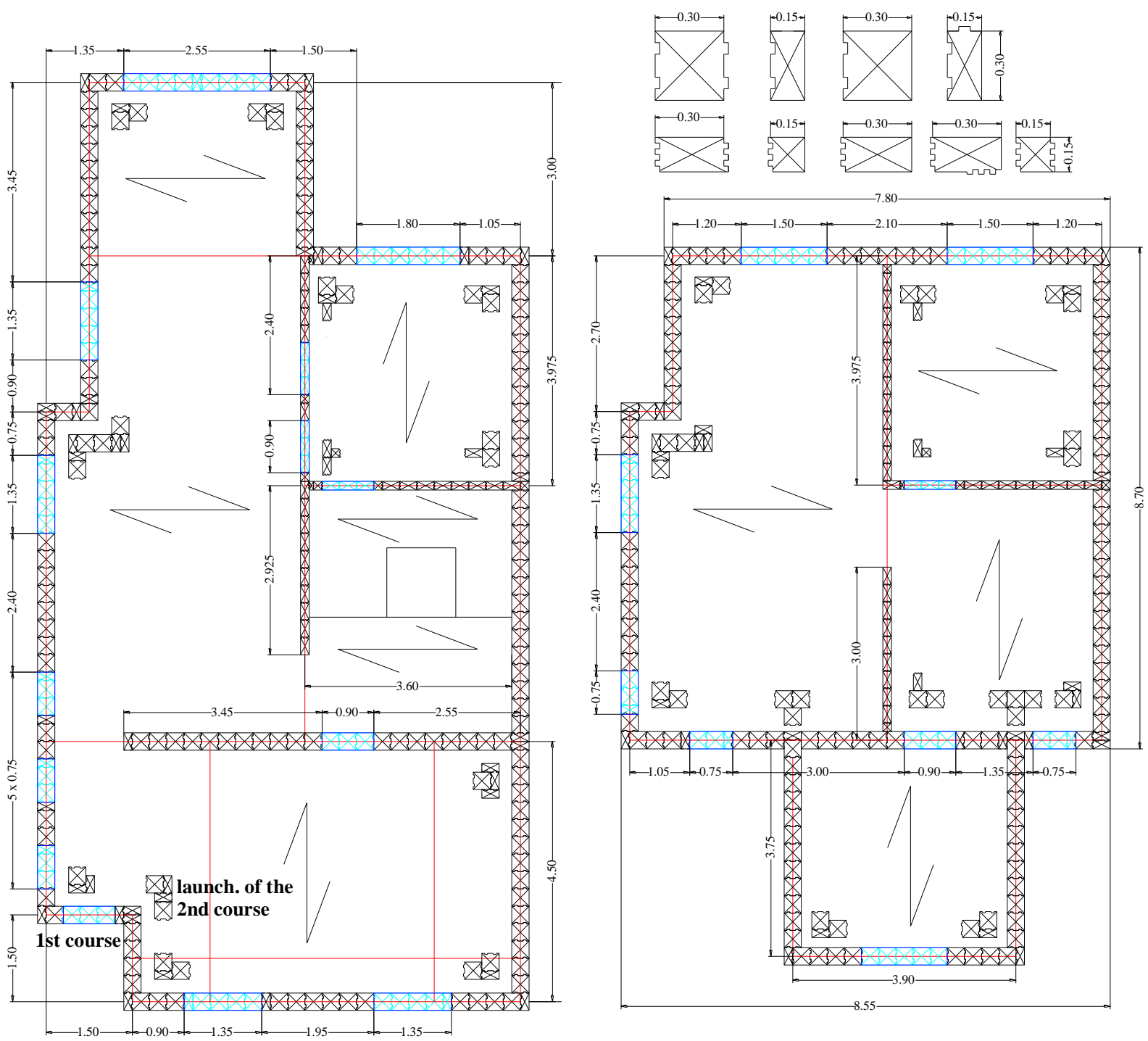

Figure 15. Structural plans of the solution in URM

The floors of the building are made with prestressed ribbed slabs, which have a thickness of 0.19 and $0.15 \mathrm{~m}$ in the accessible zones and for the ceiling/roof, respectively. The slabs are similar to those used in the original RC structure, and are subjected to dead loads of 4.5 and $3.0 \mathrm{kN} / \mathrm{m}^{2}$ and to live loads of 2.0 and $0.4 \mathrm{kN} / \mathrm{m}^{2}$, for the same areas. A bond-beam is made with the lintel-block that serves as a formwork, with a concrete section of $0.20 \times 0.35$ $\mathrm{m}^{2}$ and reinforcement of $4 \phi 10 \mathrm{~mm}$ with stirrups $\phi 6 \mathrm{~mm} @ 0.20 \mathrm{~m}(0.10 \mathrm{~m}$ at the ends $)$.

The properties for the masonry were considered according to EC6 [17], the producer declared values and selected materials, resulting in a compressive strength of $3.25 \mathrm{MPa}$, a pure shear strength of $0.1 \mathrm{MPa}$, an elastic modulus of $3250 \mathrm{MPa}$ and a shear modulus of 1300 
MPa. Additionally, the in-plane ultimate drifts for the masonry panels were assumed, according to the EC8 - Part 3 [2] and the Italian code [3] with values of $0.4 \%$ and $0.8 \%$, respectively for the shear and flexural failure modes. The weight for the masonry with plastering is $12.0 \mathrm{kN} / \mathrm{m}^{3}$.
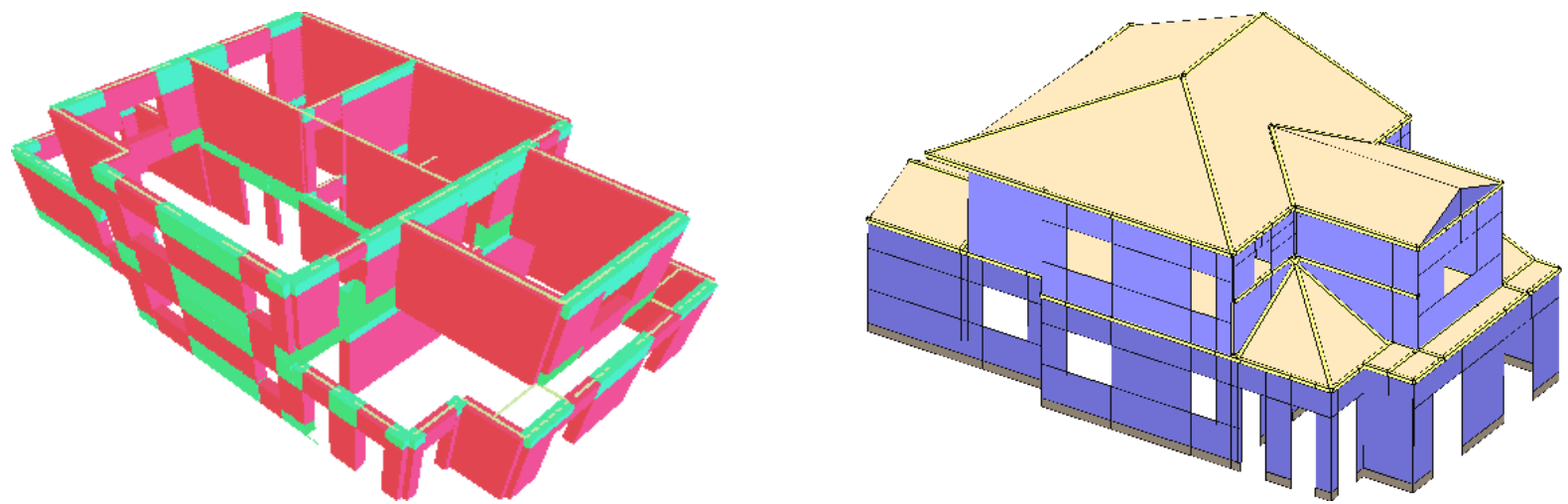

Figure 16. Tridimensional models of the building in (a) 3Muri and (b) 3DMacro

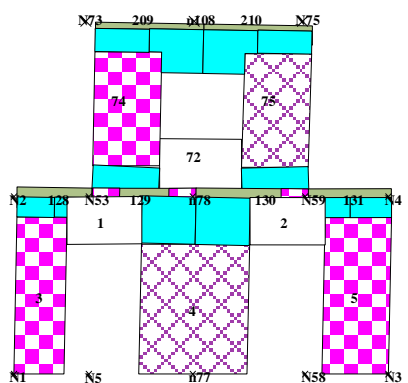

Displ. $=3 \mathrm{~mm}$

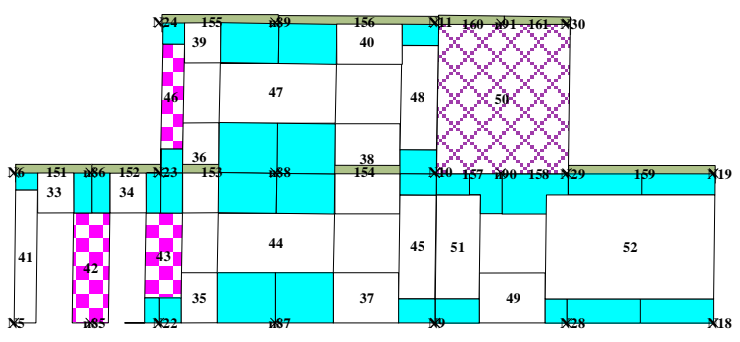

Displ. $=1 \mathrm{~mm}$

$\neg$ elastic $\square \otimes$ plastic by shear
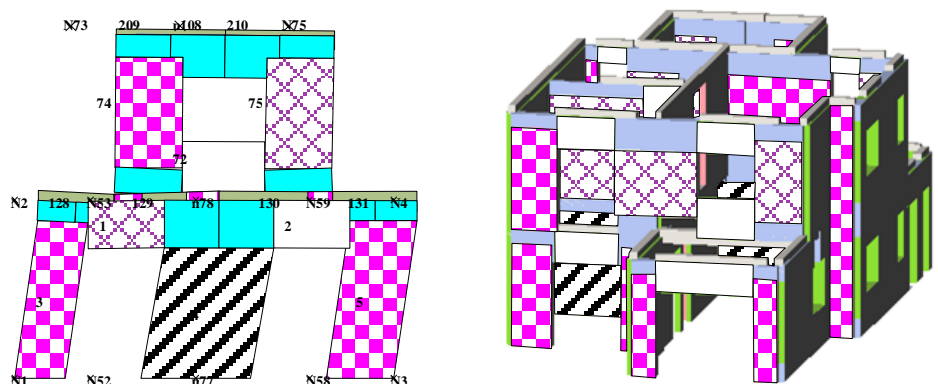

Displ. $=12 \mathrm{~mm}$

(a)

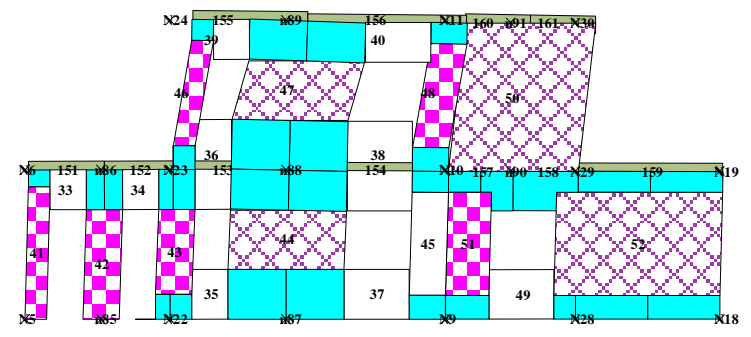

Displ. $=6 \mathrm{~mm}$

(b)

Figure 17. Damage sequence from 3 Muri corresponding to the (a) $+\mathrm{X}$ and (b) $+\mathrm{Y}$ analysis

Aiming for a comparison of the seismic response predicted by different methods, the building was modeled in the 3Muri and 3DMacro software codes, using the macro-element models presented in Figure 16. Concerning the floors, 3Muri cannot simulate inclined slabs 
and the roof was simulated in a simplified way, by overlapping the corresponding slabs at the ceiling level, to simulate the vertical loading and the diaphragm effect. In 3Muri, the floors, apart from transferring vertical loads to the walls are considered as plane stiffening elements (orthotropic membrane elements). The floors in 3DMacro are simulated as polygonal diaphragms elastically deformable, considering an orthotropic slab element.
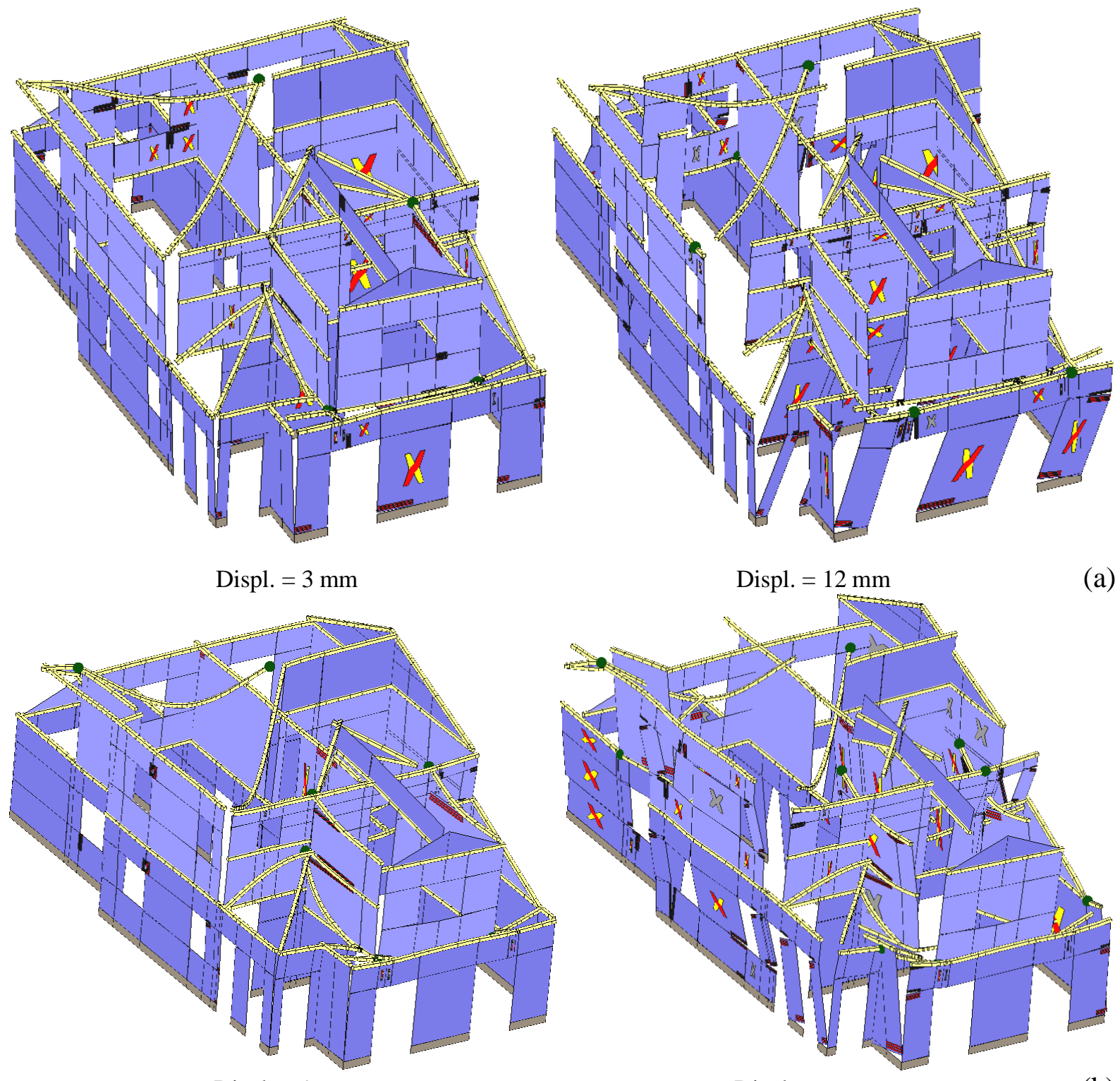

Displ. $=1 \mathrm{~mm}$

Displ. $=6 \mathrm{~mm}$

Figure 18. Damage sequence from 3DMacro corresponding to the (a) $+\mathrm{X}$ and (b) $+\mathrm{Y}$ analysis (X: diagonal shear, =: tension cracks, $\bullet$ : flexural plastic hinge)

The models were analyzed under pushover loading in the principal directions, and considering 'mass' and 'first-mode' load distributions. Concerning the $+\mathrm{X}$ and $+\mathrm{Y}$ analysis 
with first-mode load distribution, the damage sequence for the building is shown in Figures 17 and 18, respectively for 3Muri and 3DMacro. For $+X$ and regarding the front façade, a similar trend is captured in the ground storey with shear failure of the central pier and rocking of the extreme piers, and with concentration of displacements at this storey. A similar deformation mechanism and substantial shear damage are observed from 3DMacro in Figure 18a for the other wall alignments. In $+\mathrm{Y}$ the models agree when predicting rocking and shear failures respectively for slender and squat panels, and identifying a first storey mechanism. This agreement in deformation and failure mechanism allows obtaining similar capacity curves, compared in Figures 19 and 20 for the two models. They provide similar results in terms of initial stiffness, yielding displacement, base shear strength, and even decay phase.

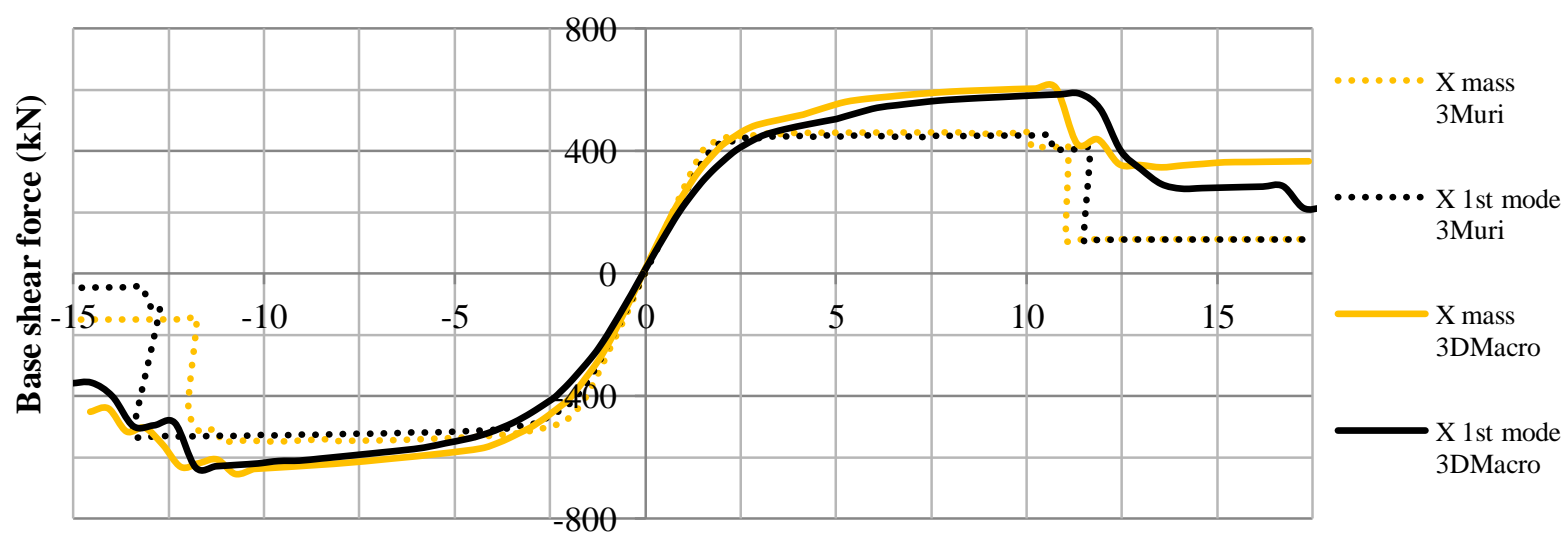

Building displacement (mm)

Figure 19. Comparison of the capacity curves in X direction from 3Muri and 3DMacro

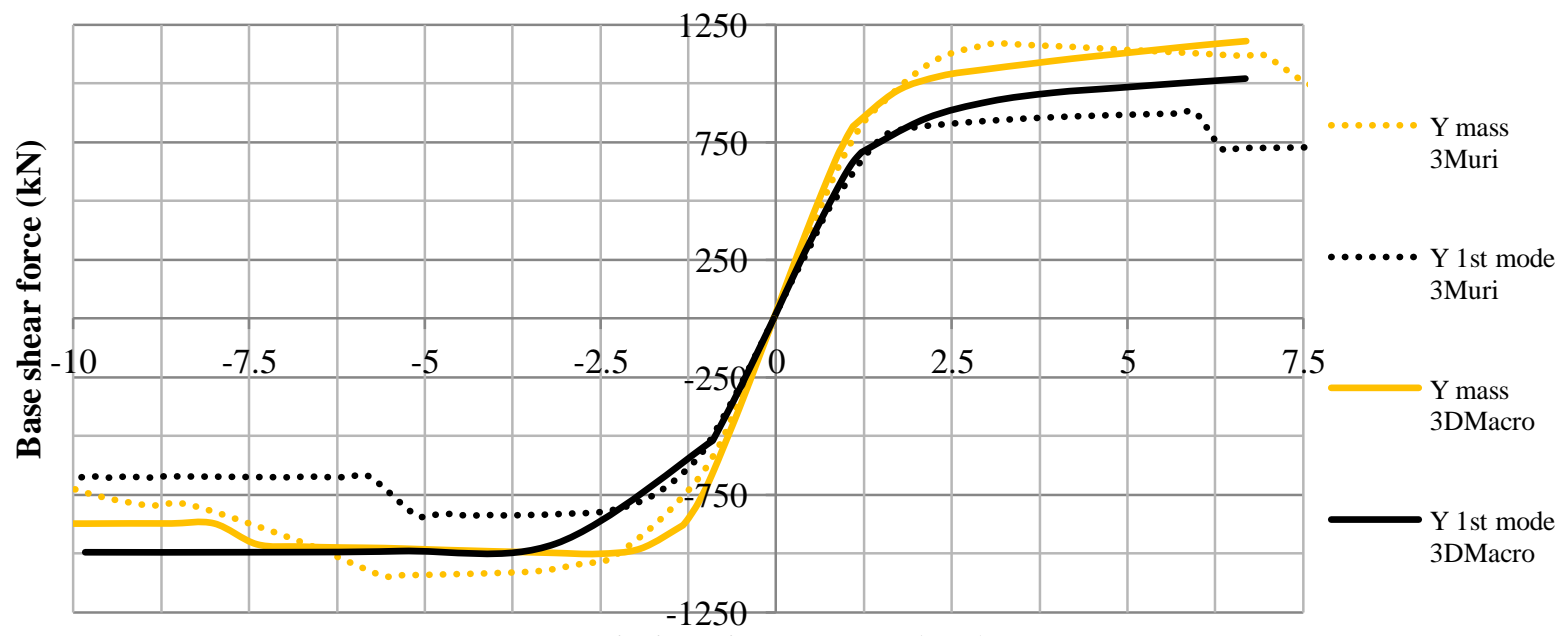

Building displacement (mm)

Figure 20. Comparison of the capacity curves in Y direction from 3Muri and 3DMacro 


\subsection{Confined masonry solution}

$\mathrm{CM}$, assumed as an intermediate solution between URM and RC structures, is now considered using the prescriptive rules from the European regulations. For the confining columns, according to EC6 [17], a longitudinal steel reinforcement must be included equivalent to $0.8 \%$ of the column cross-section area, with a minimum of $4 \phi 8 \mathrm{~mm}$. The transversal reinforcement consists of $6 \mathrm{~mm}$ diameter stirrups spaced in general of $0.20 \mathrm{~m}$ and of $0.10 \mathrm{~m}$ at the column ends. Note that the specification in codes of Latin America, e.g. the Peruvian code [28], to confine the full masonry thickness creates thermal bridges. Here, the external masonry walls are only partly confined in the thickness. The solution for the horizontal confining element is the same adopted for the URM structure in Section 3.2, namely through the use of a lintelblock that serves as lost formwork and eliminates the thermal bridge, with a section of $0.20 \times$ $0.35 \mathrm{~m}^{2}$. The structural plans for the CM solution are presented in Figure 21 .

The CM structure was modeled in the 3DMacro software [11], with the geometrical and computational models shown in Figure 22. Note that the main change with respect to the URM model is the inclusion of the reinforced concrete confining columns, which are simulated as beam finite elements with concentrated plasticity and feature a tridimensional constitutive behavior $N-M_{x}-M_{y}$. The model was then analyzed under pushover loading in the main directions and assuming load distributions proportional to the mass and to the first vibration mode.

The damage sequence for the CM model is illustrated in Figures 23 and 24 for the $+X$ and $+\mathrm{Y}$ analysis with 'first-mode' load distribution, corresponding to different displacement levels. For both analyses, damage in the building starts to be relevant for $1 \mathrm{~mm}$ displacement, when several masonry panels develop tensile cracks in the interfaces and also diagonal shear cracking. For a displacement of $4 \mathrm{~mm}$ damage spreads widely, to all walls of the building. 
Then, damage evolves with increasing deformation due to the progressive formation of flexural plastic hinges at the ends of the confining elements.

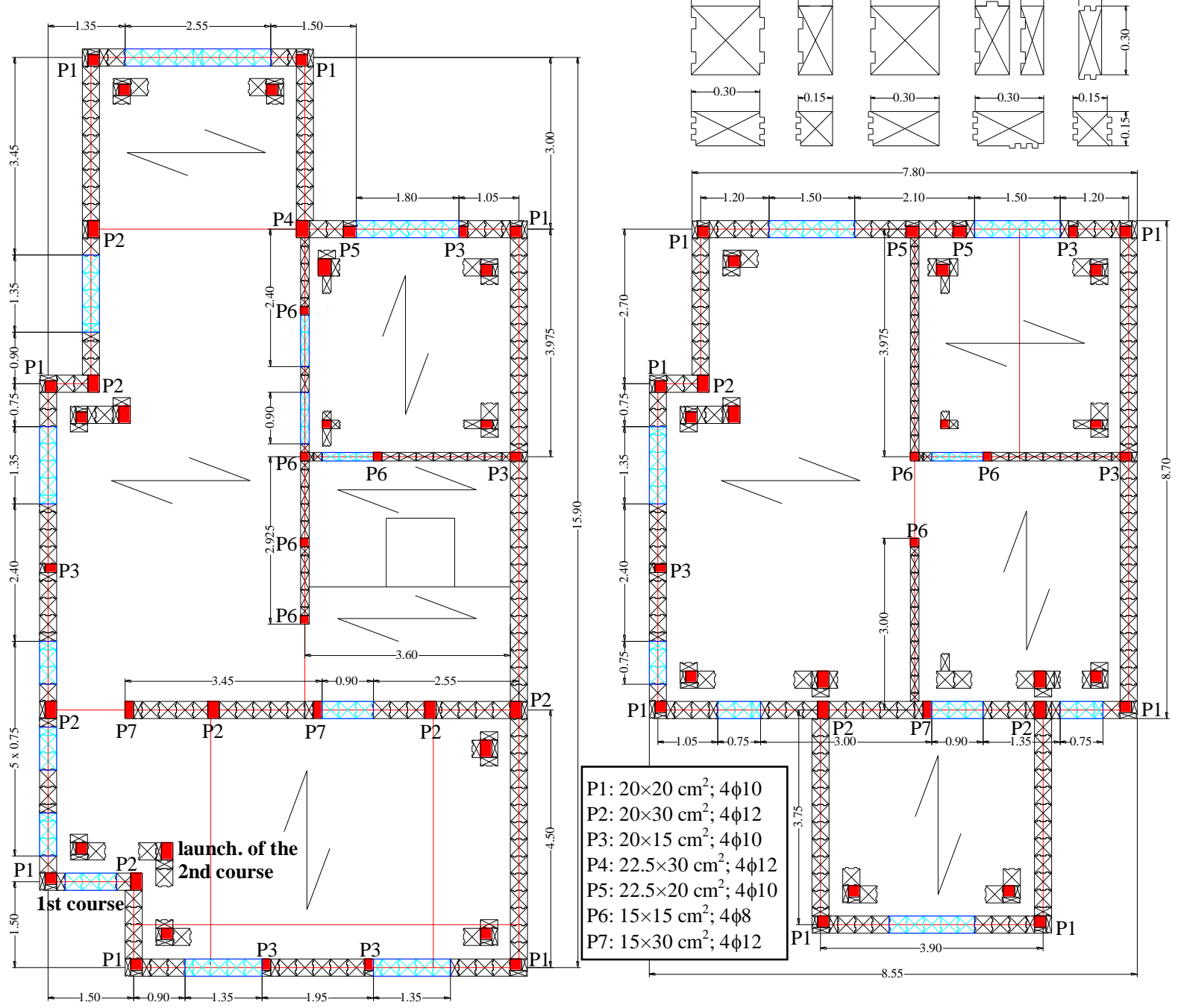

Figure 21. Structural plans of the constructive solution in CM
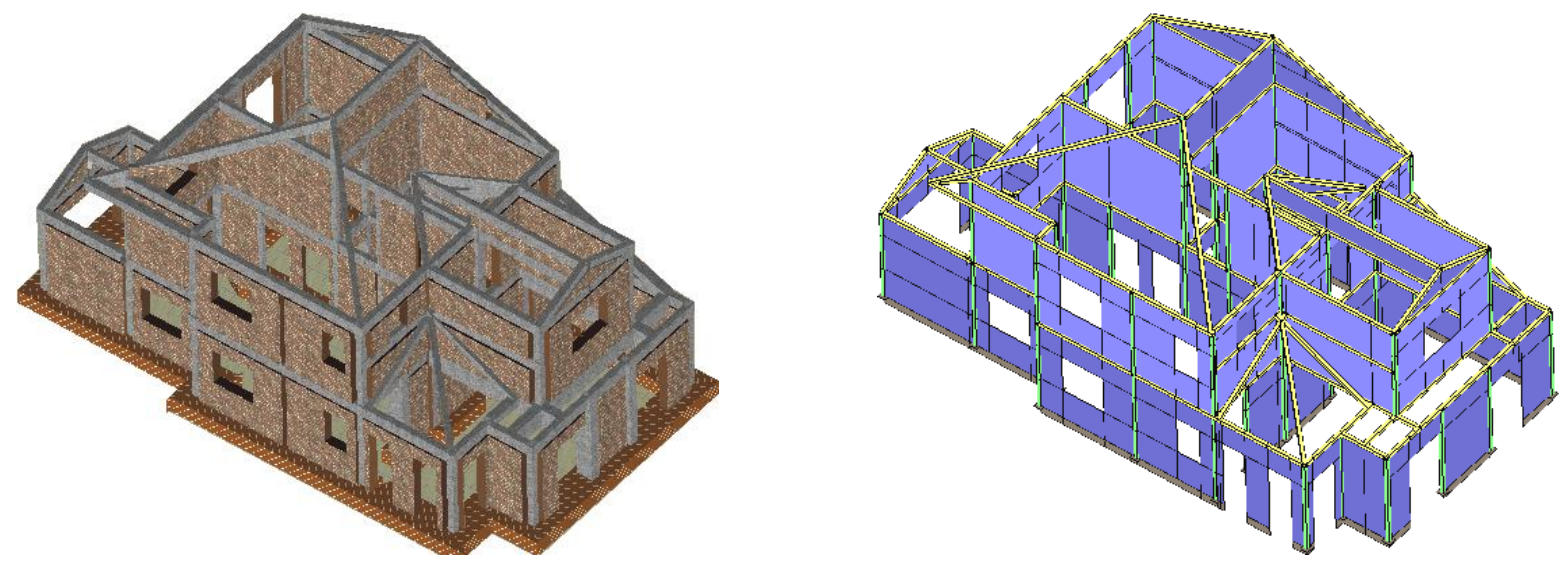

Figure 22. Geometrical and computational models in 3DMacro of the CM building 
The capacity curves are given in Figures 25 and 26, together with a comparison with the results from the URM solution. An increase of the base shear capacity is clearly observed for the $\mathrm{X}$ direction. Still, a sharp decrease of capacity is found after peak due to small number of confined panels and absence of walls at first storey in the left part of the building. The high degradation of the confined walls at peak load generates a ground-storey mechanism. Concerning the $\mathrm{Y}$ direction, a remarkable improvement of the base shear strength and ductility is observed.
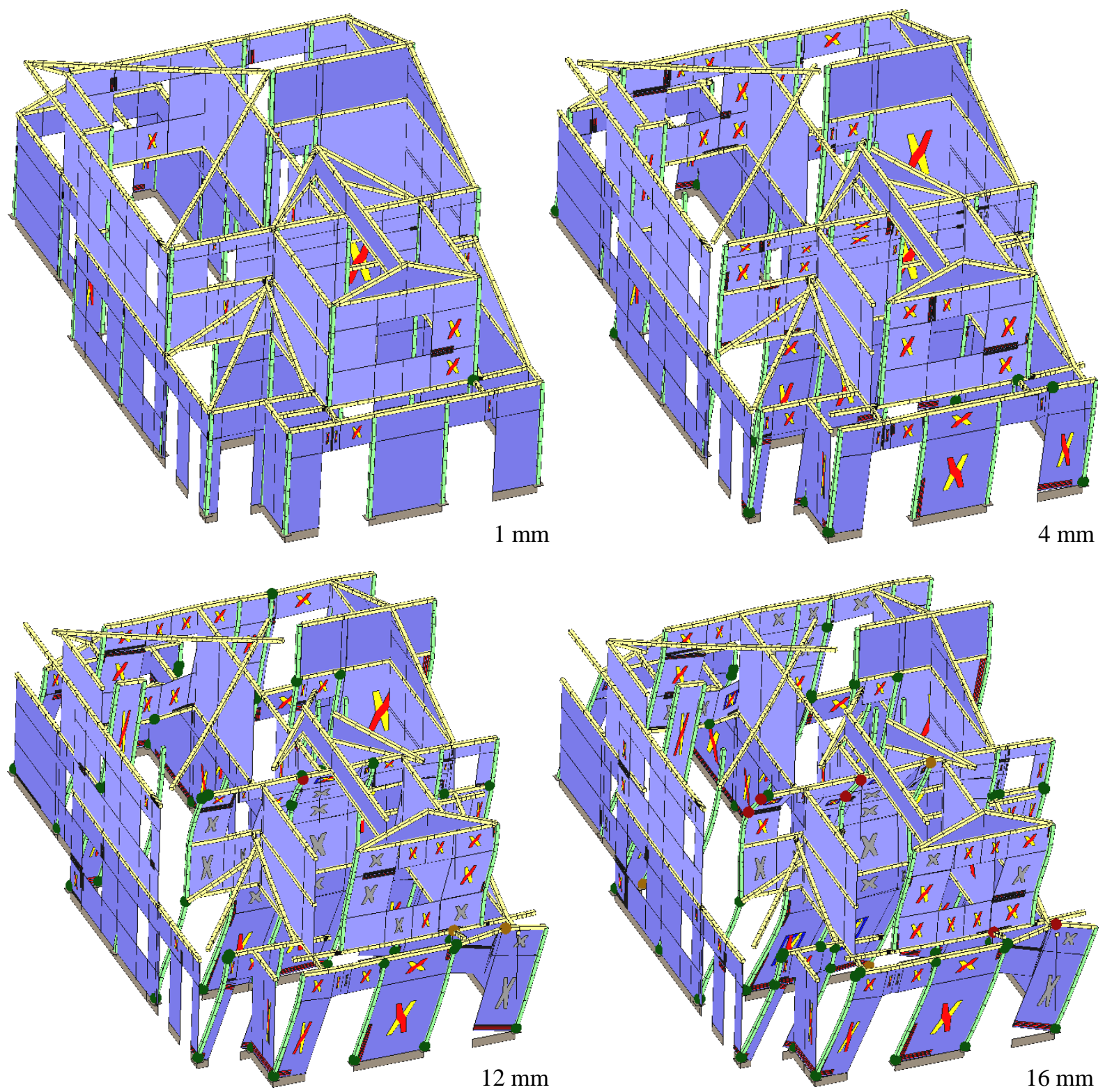

Figure 23. Damage sequence for the $+X$ analysis with 1 st-mode load distribution (X: diagonal shear, =: tension cracks, $\bullet$ : flexural plastic hinge) 

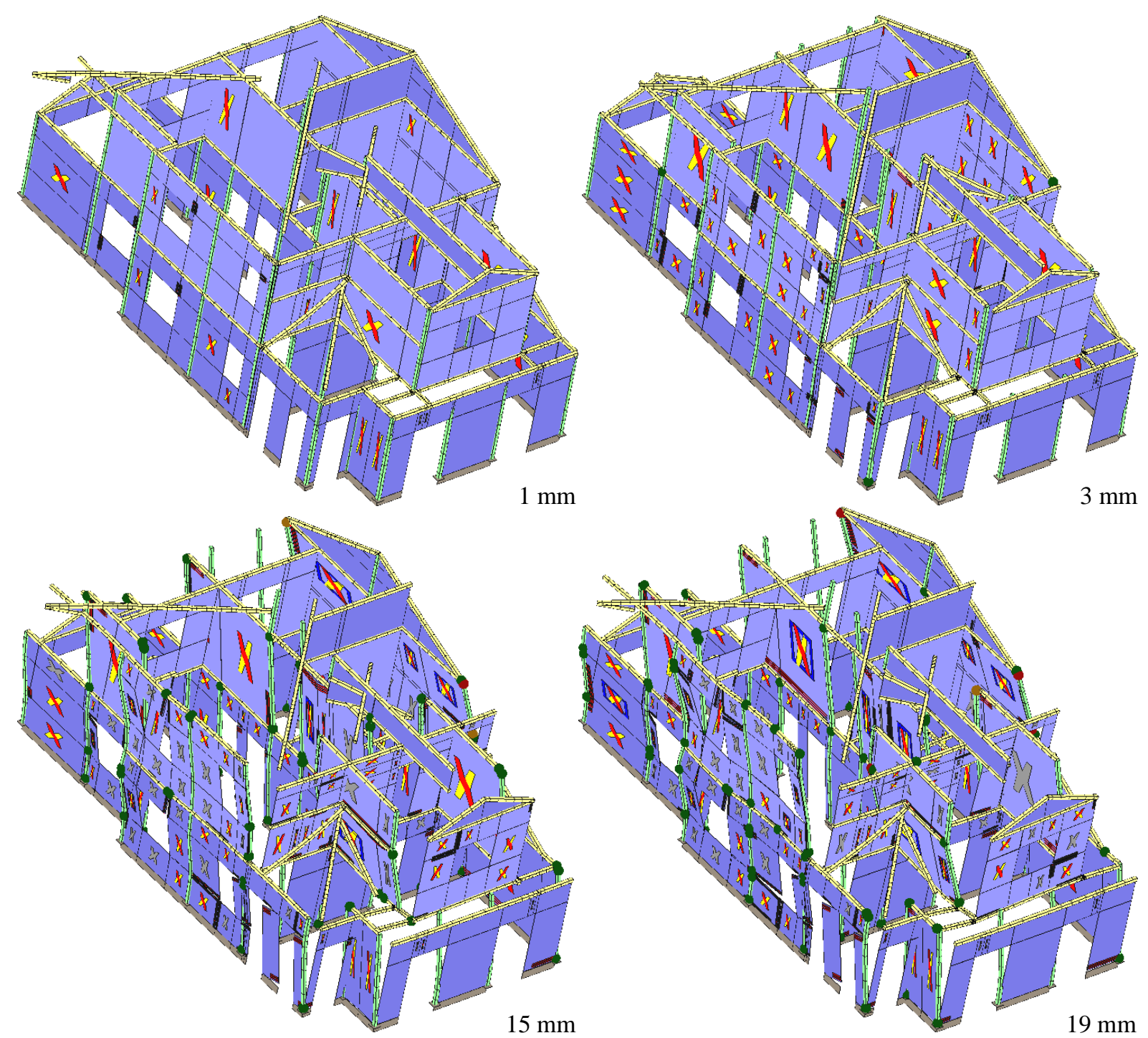

Figure 24. Damage sequence for the $+Y$ analysis with 1st-mode load distribution (X: diagonal shear, $=$ : tension cracks, $\bullet$ : flexural plastic hinge)

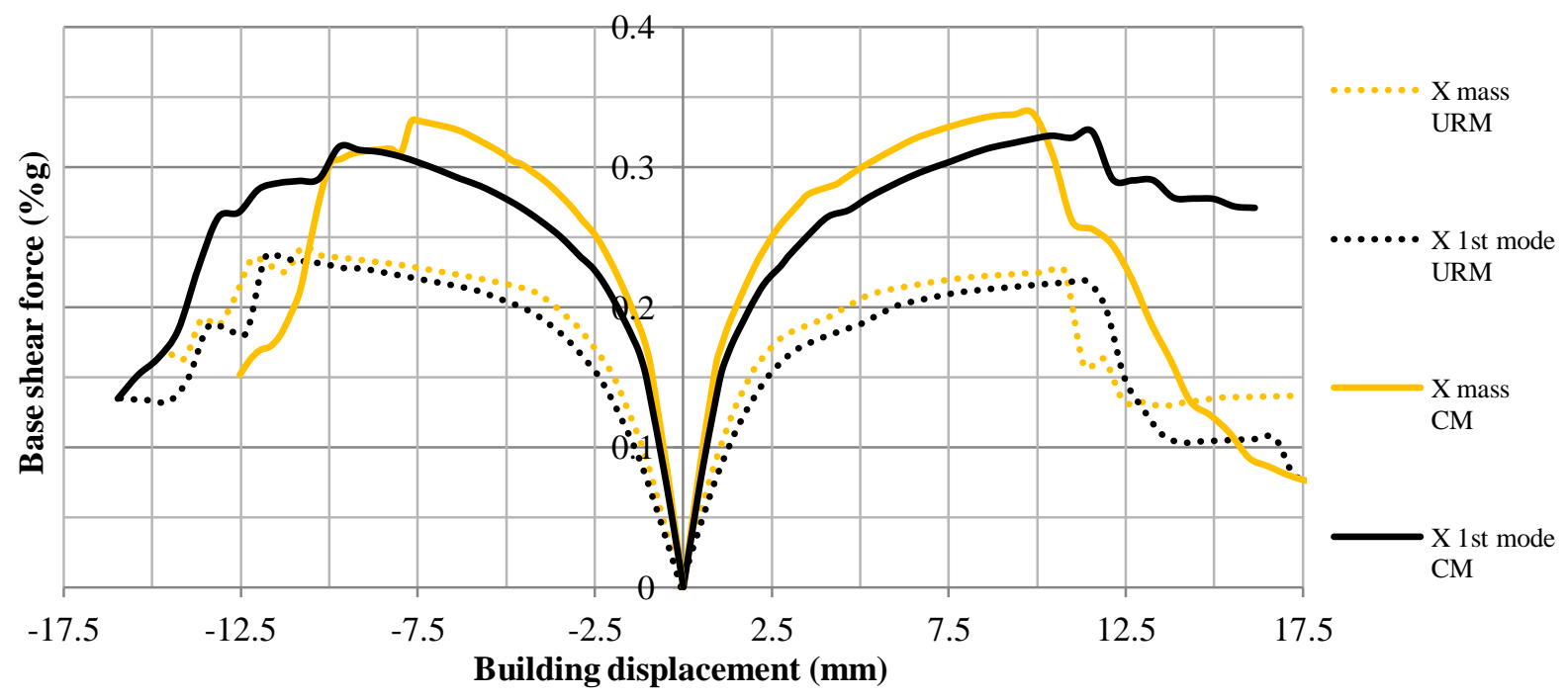

Figure 25. Capacity curves in X direction for the URM and CM models in 3DMacro 


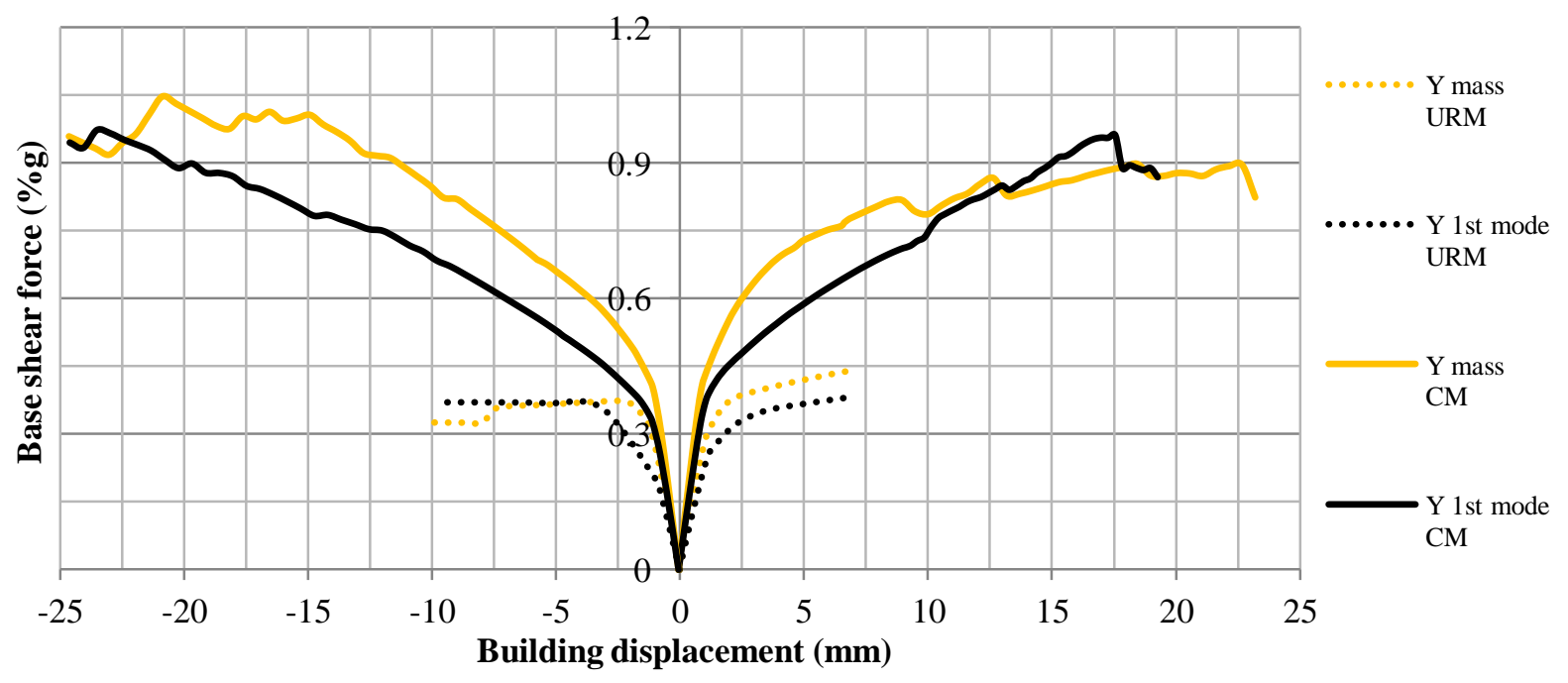

Figure 26. Capacity curves in Y direction for the URM and CM models in 3DMacro

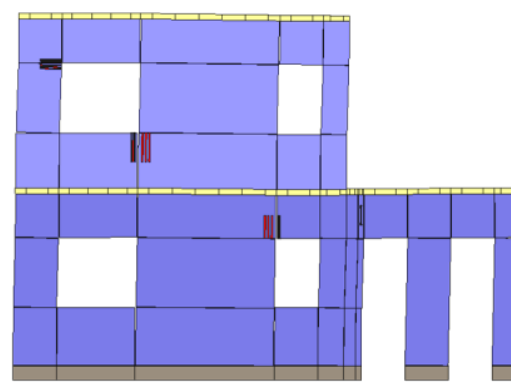

$1 \mathrm{~mm}$

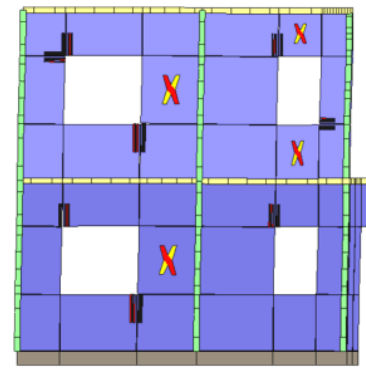

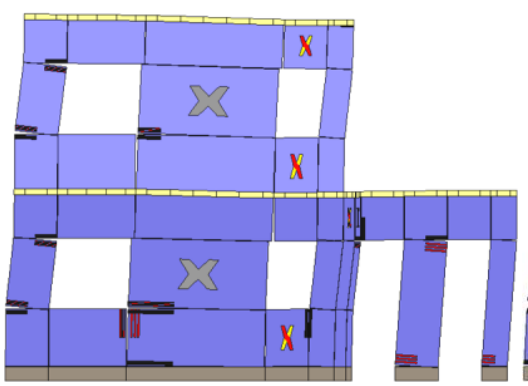

$3 \mathrm{~mm}$

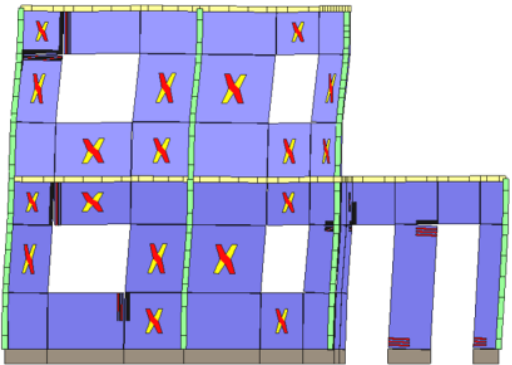

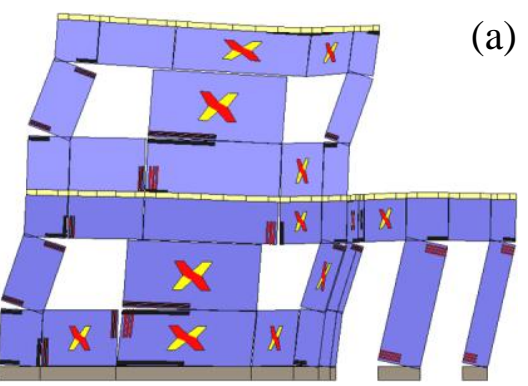

$10 \mathrm{~mm}$

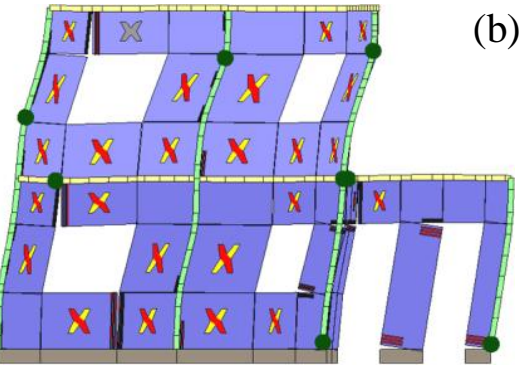

Figure 27. Damage scenario in (a) URM and (b) CM frames for the $-\mathrm{Y}$ analysis with 1stmode load distribution (X: diagonal shear, =: tension cracks, $\bullet$ : flexural plastic hinge)

In the $\mathrm{CM}$, the presence of confinement constitutes a constraint for the masonry infill, which induces a damage trend different of that verified for URM. Referring to frames presented in Figure 27 of the building lateral façade, it is observed that for the URM wall the damage is initially by tension cracking in panel edges and with subsequent rocking of the slender panels, while for the CM frame early damage occurs due to diagonal cracking which 
propagates along the wall diagonals inducing flexural hinges in the confinements. For a displacement of $10 \mathrm{~mm}$, the URM wall is seriously damaged, while the CM frame presents widespread cracking but damage is controlled.

\subsection{Comparative analysis}

An evaluation supported by the analyses is now made more in detail of the seismic capacity of URM and CM structural solutions. In particular, a discussion on the behavior factors to use in force-based safety verifications is made. Regarding economic aspects, a comparison is made between the construction costs of the URM and CM structures against the usual RC solution.

Figure 28 presents the values of the reference peak ground acceleration on type A ground (rock formations) as defined in EC8 [1], $a_{g, u}$, corresponding to the ultimate displacement capacity for the building according to the considered codes [2-3]. The building is subjected to a type 2 spectrum ("near-field earthquake") and all acceleration values were derived using the N2 method [30] in the software codes. The $a_{g, u}$ can be interpreted as the maximum ground acceleration supported by the building for a condition of near collapse or ultimate state. Regarding the application of a force-based approach, namely the lateral force method of analysis in EC8, the base shear force $F_{b}$ is computed as

$$
F_{b}=S_{d}(T) \cdot m=a_{g} \cdot S \frac{2.5}{q} \cdot m
$$

where $S_{d}(T)$ is the ordinate of the design spectrum at the fundamental period of vibration $T$ of the building in the direction considered, $m$ is the total mass of the building, $S$ is the soil factor and $q$ is the behavior factor. Here, it is assumed that the structure is behaving in the shortperiod range. On the other hand, a design ground acceleration can be considered, associated to the yield strength $F_{y}$ of an energy-equivalent bilinear response to the building capacity curve, $a_{g, y}$. Then, by assuming that $F_{b}$ is equal to $F_{y}$, the reduced acceleration $a_{g, y}$ can be computed as

$a_{g, y}=\frac{a_{g, u}}{q_{r}}=\frac{F_{y}}{2.5 \cdot S \cdot m}$ 
where $q_{r}$ can be taken as an approximation to the behavior factor $q$ in EC8, as it reflects the reduction of the elastic acceleration spectrum to the requested acceleration in the capacity curve, when considering the inelastic response of the building.

The values of the $q_{r}$ reduction factor (computed as the ratio between the two defined accelerations, $a_{g, u}\left(a_{g, y}\right)$ establish a correspondence between the considered force-based and displacement-based assessment approaches. It is noted that the $q_{r}$ values were obtained through an expedite way and for a very particular building configuration, but two conclusions are possible: (1) in the URM structure, the computed $q_{r}$ values (2.7-3.7) are significantly higher than the specified values of the behavior factor $q(1.5-2.5)$ in EC8; and (2) the $q_{r}$ values for the CM structure (1.8-3.0) are in the range for $q$ in EC8, although being lower than the computed $q_{r}$ values for the URM structure. Therefore, the application of the lateral force method of analysis with the recommended $q$ values in EC8 seems too conservative for the case of URM buildings, as corroborated from experimental and analytical studies by Tomaževič [31] and Magenes [32], respectively. The finding of $q_{r}$ values for the CM building lower than those for the URM building is believed to be due to a particular building configuration, with an excess of capacity in a rather weak part of the building that cannot be redistributed. This is considered a conclusion that cannot be generalized for all masonry buildings. It is also noted that, still, the capacity of the CM structure is higher than that of the URM structure.

The solution originally considered for the dwelling was a RC structure. Using two software codes (3Muri and 3DMacro) it was demonstrated that the URM structural solution allows a more than sufficient seismic capacity. The computation in 3Muri referring to zones with prevalence to type 2 spectra ("near-field earthquakes") indicates that seismic safety is ensured up to a reference peak acceleration $\left(a_{g R}\right)$ of $1.7 \mathrm{~m} / \mathrm{s}^{2}$. For the case of type 1 spectra ("far-field earthquakes") the allowed $a_{g R}$ is $1.5 \mathrm{~m} / \mathrm{s}^{2}$. On the other hand, from the simulation in 
3DMacro the CM structural solution withstands an $a_{g R}$ of $2.5 \mathrm{~m} / \mathrm{s}^{2}$ in the case of "near-field earthquakes" and an $a_{g R}$ of $2.0 \mathrm{~m} / \mathrm{s}^{2}$ in the case of "far-field earthquakes", which denotes this structural typology as an alternative to RC structures even in regions of high seismicity.

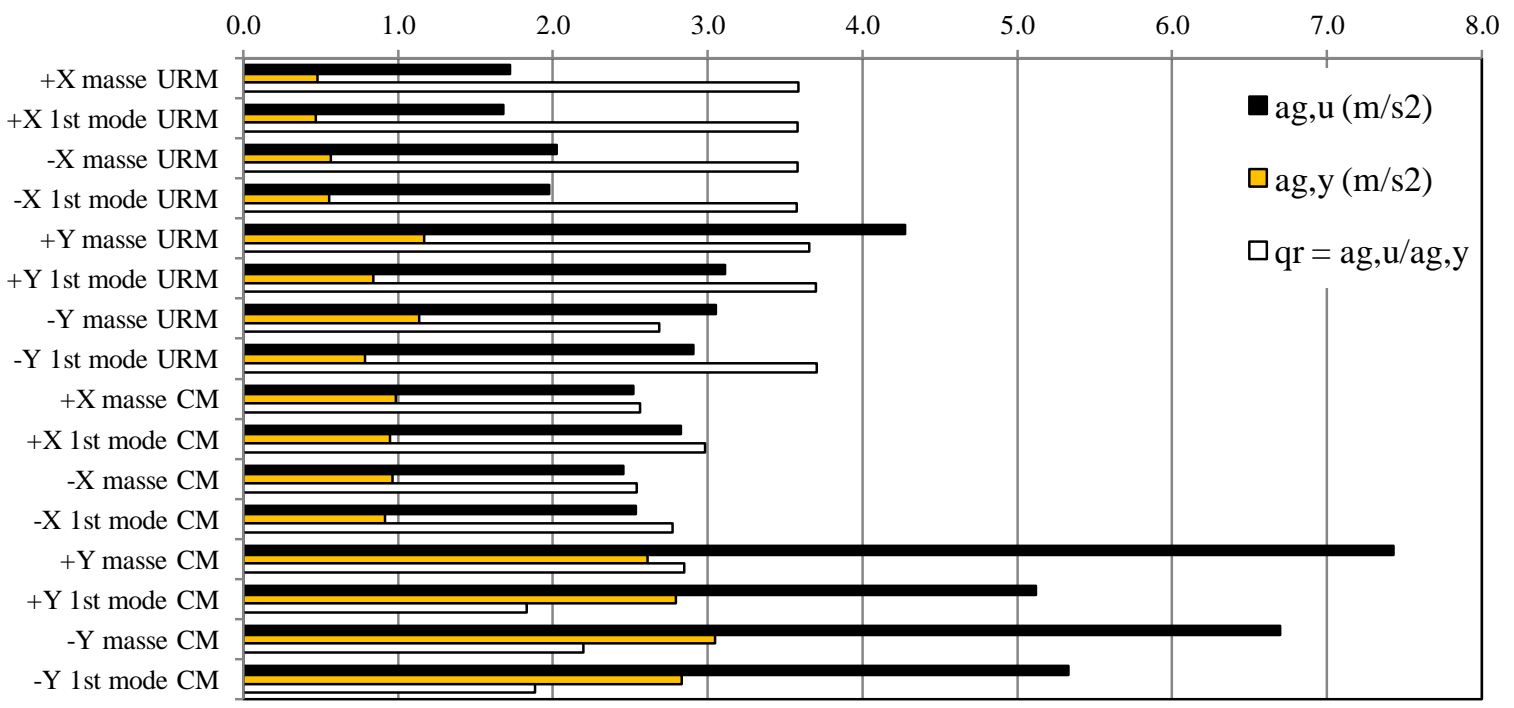

Figure 28. Evaluation of maximum acceleration capacity and corresponding reduction factors

In order to support a choice for the structural solution also regarding the economic aspect, the costs associated to the construction of the dwelling with RC, URM and CM typologies are now estimated. Note that the RC structure presents a double-wythe cavity wall that includes internal insulation to comply with the thermal code, while the masonry structures feature a single leaf wall. By adopting 2013 prices in the Portuguese construction market, the costs of the structure for the different solutions are presented in Figure 29. Note that the values are expressed as a percentage of the total cost of the RC structure.

In the case of the structural masonry solutions, although the block-work is more expensive due to the higher quality of the units, there is significant economy in the foundations, which have small section since the stresses are low and distributed through the walls, and in the RC superstructure. Note that the masonry work presents a higher cost for the $\mathrm{CM}$, due to cutting of blocks and application of thermal insulation in the columns. The URM and CM solutions allow a total cost reduction of, respectively, $24 \%$ and $16 \%$ when comparing 
to the RC structure. This adds to a faster construction process and better long term / service performance as a result of better durability and lower cracking and deformation.

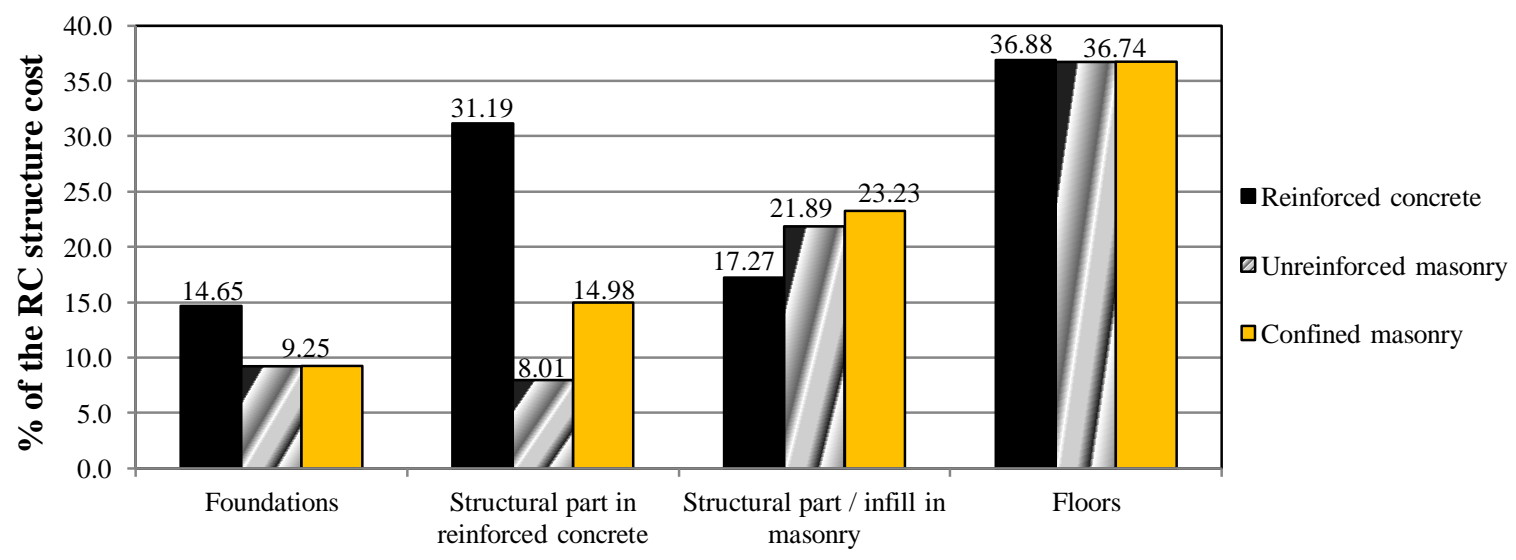

Figure 29. Summary of construction costs for different structures

\section{Conclusions}

The present work offers a contribution regarding the design and construction of cost-effective buildings in seismic regions. For this purpose, the tools available for the seismic design of unreinforced and confined masonry buildings are presented and validated against experimental evidence. With reference to an actual case of a single family housing, simulations are carried to assess its earthquake-resistant capabilities and an evaluation of the construction costs of masonry solutions is made in comparing with the usual RC frame structure.

In general and referring to the validation of experimental tests, the analysis tools available allowed a satisfactory prediction of the capacity curve from the pushover analysis, namely in terms of initial stiffness, base shear strength and displacement capacity, thus being accurate to use in performance-based design. Furthermore, the software codes allow simulating the specificities of real masonry building configurations.

Using a typical house in the southern Europe as case study, structural masonry solutions allowed ensuring seismic safety up to large ground acceleration levels, namely 
$0.15 g$ and $0.20 g$ for URM and CM structures, respectively. Furthermore, these solutions allow a cost reduction of the structure respectively of $24 \%$ and $16 \%$ when considering the RC structure as reference. For the URM structure, it was demonstrated that a very conservative design is obtained using the force-based method specified in EC8 [1], due to the consideration of very conservative values for the behavior factor.

The simulation of the real dynamic behavior of a masonry building is a very complex task. In order to simplify, the validation of the presented macro-element models against experimental results and also its application to a typical building allows to obtain an approach

to the pushover response of the studied structures, which is assumed to provide a representative indication of the seismic behavior, particularly regarding the application of seismic codes.

\section{Acknowledgement}

The first author acknowledges the financial support from the Portuguese Foundation for Science and Technology (FCT) through the Ph.D. grant SFRH/BD/41221/2007.

\section{References}

[1] EN 1998-1:2004. Eurocode 8: Design of structures for earthquake resistance - Part 1: General rules, seismic actions and rules for buildings. Brussels: European Committee for Standardization; 2004.

[2] EN 1998-3:2005. Eurocode 8: Design of structures for earthquake resistance - Part 3: Assessment and retrofitting of buildings. Brussels: European Committee for Standardization; 2005.

[3] IBC. Norme tecniche per le costruzioni ("Italian building code"), Ministerial Decree dated of 14-01-2008. Rome: Ministero delle Infrastrutture e dei Trasporti; 2008 [in Italian]. 
[4] Lourenço PB. Computations of historical masonry constructions. Prog Struct Eng Mater 2002;4(3):301-19.

[5] Ramos LF, Lourenço PB. Advanced numerical analysis of historical centers: A case study in Lisbon, Eng Struct 2004;26(9):1295-310.

[6] Lourenço PB, Krakowiak KJ, Fernandes FM, Ramos LF. Failure analysis of Monastery of Jerónimos, Lisbon: How to learn from sophisticated numerical models?. Eng Fail Anal 2007;14(2):280-300.

[7] Tomaževič M. The computer program POR. Report ZRMK, Ljubljana; 1978 [in Slovenian].

[8] Marques R, Lourenço PB. Possibilities and comparison of structural component models for the seismic assessment of modern unreinforced masonry buildings. Comput Struct 2011;89(21-22):2079-91.

[9] Calliari R, Manzini CF, Morandi P, Magenes G, Remino M. 2010. User manual of ANDILWall, Version 2.5. Rome: ANDIL Assolaterizi; 2010 [in Italian].

[10] Lagomarsino S, Penna A, Galasco A, Cattari S. User guide of TreMuri (Seismic analysis program for 3D masonry buildings), Version 1.7.34. University of Genoa; 2009.

[11] Gruppo Sismica. Theoretical manual of the 3DMacro software, beta version. Catania: Gruppo Sismica; 2013.

[12] Magenes G, Calvi GM, Kingsley R. Seismic testing of a full-scale, two-story masonry building: Test procedure and measured experimental response. In: Experimental and numerical investigation on a brick masonry building prototype: Numerical prediction of the experiment. Report 3.0, Pavia: G.N.D.T.; 1995.

[13] Yi T, Moon FL, Leon RT, Kahn LF. Lateral load tests on a two-story unreinforced masonry building. J Struct Eng-ASCE 2006;132(5):643-52. 
[14] Cappi A, Castellani A, Gradori G, Locatelli P. Strengthening and repairing of masonry walls damaged by shear actions in their own planes. Publication N. 701, Politecnico di Milano: Istititu di Scienza e Tecnica delle Construzione; 1975.

[15] Turnšek V, Čačovič F. Some experimental results on the strength of brick masonry walls. In: Proceedings of the 2nd International Brick Masonry Conference. Stoke-on-Trent; 1970, p. $149-156$.

[16] OPCM 3431/2005. Ordinanza P.C.M. N. 3431 dated of 03-05-2005, Modification of Ordinanza N. 3274 of 20-03-2003, "General criteria for the seismic zonation of the national territory and technical normative for buildings in seismic zones"; 2005 [in Italian].

[17] EN 1996-1-1:2005. Eurocode 6: Design of masonry structures - Part 1-1: General rules for reinforced and unreinforced masonry structures. Brussels: European Committee for Standardization; 2005.

[18] Gambarotta L, Lagomarsino S. On the dynamic response of masonry panels. In: Gambarotta L, editor. Proceedings of the Italian Conference "La meccanica delle murature tra teoria e progetto". Messina; 1996, p. 451-462 [in Italian].

[19] Penna A. A macroelement procedure for nonlinear dynamic analysis of masonry structures, Ph.D. thesis. Politecnico di Milano; 2002 [in Italian].

[20] Parisi F, Augenti N, Prota A. The role of spandrels within masonry walls with openings: an experimental investigation. In: Proceedings of the Ninth Pacific Conference on Earthquake Engineering: Building an Earthquake-Resilient Society, Auckland; 2011, pp. 232.

[21] Marques R. New methodologies for seismic design of unreinforced and confined masonry structures, $\mathrm{PhD}$ thesis. Guimarães: University of Minho; 2012. <http:// www.civil.uminho.pt/masonry>

[22] Terán-Gilmore A, Zúñiga-Cuevas O, Ruiz-García J. Displacement-based seismic assessment of low-height confined masonry buildings. Earthq Spectra 2009;25(2):439-64. 
[23] Marques R, Lourenço PB. A model for pushover analysis of confined masonry structures: implementation and validation. B Earthq Eng 2013;11(6):2133-50.

[24] Calderini C, Cattari S, Lagomarsino S. Numerical investigations on the seismic behaviour of confined masonry walls. In: Proceedings of the 2008 Seismic Engineering Conference "Commemorating the 1908 Messina and Reggio Calabria Earthquake". AIP Conference Proceedings 1020; 2008, p. 816-823.

[25] Caliò I, Marletta M, Pantò B. A new discrete element model for the evaluation of the seismic behaviour of unreinforced masonry buildings. Eng Struct 2012;40:327-38.

[26] Caliò I, Cannizzaro F, D’Amore E, Marletta M, Pantò B. A new discrete-element approach for the assessment of the seismic resistance of mixed masonry and reinforced concrete buildings. In: Proceedings of the 2008 Seismic Engineering Conference "Commemorating the 1908 Messina and Reggio Calabria Earthquake". AIP Conference Proceedings 1020; 2008, p. 832-839.

[27] Zavala C, Honma C, Gibu P, Gallardo J, Huaco G. Full scale on line test on two story masonry building using handmade bricks. In: Proceedings of the 13th World Conference on Earthquake Engineering, Vancouver; 2004, pp. 2885.

[28] SENCICO 2006. Reglamento nacional de edificaciones. Norma técnica E.070: Albañilería ("Peruvian building code: Normative for masonry buildings"). Lima: Ministerio de Vivienda, Construcción y Saneamiento; 2006 [in Spanish].

[29] Torre P. Parametric analysis of masonry structures, MSc dissertation. Guimarães: University of Minho; 2008 [in Portuguese].

[30] Fajfar P, Fischinger M. N2 - a method for nonlinear seismic analysis of regular buildings. In: Proceedings of the 9th World Conference on Earthquake Engineering, TokyoKyoto; 1988, Vol. 5, p. 111-116. 
[31] Tomaževič M. Damage as a measure for earthquake-resistant design of masonry structures: Slovenian experience. Can J Civil Eng 2007;34:1403-12.

[32] Magenes G. Masonry building design in seismic areas: recent experiences and prospects from a European standpoint. In: Proceedings of the 1st European Conference on Earthquake Engineering and Seismology, Geneva; 2006, keynote K9. 


\section{Figure captions}

Figure 1. Earthquakes in Europe with magnitude greater than 5 in the period 1973-2006 [Source: U.S. National Earthquake Information Center]

Figure 2. Schematization of wall models in (a) SAM II, (b) TreMuri and (c) 3DMacro

Figure 3. Views of the masonry structure tested under lateral static loading [14]

Figure 4. Wall models in (a) ANDILWall/SAM II, (b) TreMuri and (c) 3DMacro

Figure 5. Experimental envelopes and capacity curves obtained for the several models

Figure 6. Evolution of the (a) axial and (b) shear forces in the piers

Figure 7. Response of the center spandrel: (a) evolution of the axial and shear forces;

(b) crack in the experimental model [14]

Figure 8. Wall deformed shape and damage according to models: (a) SAM II, (b) 3Muri, (c) TreMuri and (d) 3DMacro (50 times magnification)

Figure 9. Discrete macro-element: (a) interface model, (b) frame element and (c) example of interaction domain $\mathrm{N}-\mathrm{M}_{\mathrm{x}}-\mathrm{M}_{\mathrm{y}}$

Figure 10. Building tested by Zavala et al. [27]: (a) structural plan and (b) test set-up 
Figure 11. Geometrical and computational models in 3DMacro of the building

Figure 12. Experimental against predicted damage in the South wall for three drift levels

Figure 13. Comparison of the predicted envelopes in 3DMacro against the experimental response (color figure available online)

Figure 14. Architectural drawings of the dwelling: plans and elevation views

Figure 15. Structural plans of the solution in URM

Figure 16. Tridimensional models of the building in (a) 3Muri and (b) 3DMacro

Figure 17. Damage sequence from 3 Muri corresponding to the (a) $+\mathrm{X}$ and (b) $+\mathrm{Y}$ analysis

Figure 18. Damage sequence from 3DMacro corresponding to the (a) $+\mathrm{X}$ and (b) $+\mathrm{Y}$ analysis (X: diagonal shear, =: tension cracks, $\bullet$ : flexural plastic hinge)

Figure 19. Comparison of the capacity curves in $\mathrm{X}$ direction from 3Muri and 3DMacro

Figure 20. Comparison of the capacity curves in Y direction from 3Muri and 3DMacro

Figure 21. Structural plans of the constructive solution in $\mathrm{CM}$ 
Figure 22. Geometrical and computational models in 3DMacro of the CM building

Figure 23. Damage sequence for the $+X$ analysis with 1st-mode load distribution (X: diagonal shear, =: tension cracks, •: flexural plastic hinge)

Figure 24. Damage sequence for the $+Y$ analysis with 1st-mode load distribution (X: diagonal shear, $=$ : tension cracks, $\bullet$ : flexural plastic hinge)

Figure 25. Capacity curves in X direction for the URM and CM models in 3DMacro

Figure 26. Capacity curves in Y direction for the URM and CM models in 3DMacro

Figure 27. Damage scenario in (a) URM and (b) CM frames for the $-\mathrm{Y}$ analysis with 1stmode load distribution (X: diagonal shear, =: tension cracks, $\bullet$ : flexural plastic hinge)

Figure 28. Evaluation of maximum acceleration capacity and corresponding reduction factors

Figure 29. Summary of construction costs for different structures 